\title{
Estimation of Aerial Deposition and Foliar Uptake of Xenobiotics: Assessment of Current Models
}
S. O. Link
J. G. Droppo
R. J. Fellows
P. Van Voris
D. A. Cataldo

October 1987

Prepared for the

U.S. Environmental Protection Agency under a Related Services Agreement with the Department of Energy

Contract DE-AC06-76RLO 1830

Pacific Northwest Laboratory Operated for the U.S. Department of Energy by Battelle Memorial Institute 


\section{DISCLAIMER}

This report was prepared as an account of work sponsored by an agency of the United States Government. Neither the United States Government nor any agency thereof, nor Battelle Memorial Institute, nor any of their employees, makes any warranty, expressed or implied, or assumes any legal liability or responsibility for the accuracy, completeness, or usefulness of any information, apparatus, product, or process disclosed, or represents that its use would not infringe privately owned rights. Reference herein to any specific commercial product, process, or service by trade name, trademark, manufacturer, or otherwise, does not necessarily constitute or imply its endorsement, recommendation, or favoring by the United States Government of any agency thereof, or Battelle Memorial Institute. The views and opinions of authors expressed herein do not necessarly state or reflect those of the United States Government or any agency thereof, or Battelle Memorial Institute.

\section{PACIFIC NORTHWEST LABORATORY operated by \\ BATTELLE MEMORIAL INSTITUTE for the UNITED STATES DEPARTMENT OF ENERGY under Contract DE-AC06-76RLO 1830}

\begin{tabular}{|c|c|}
\hline \multirow{2}{*}{\multicolumn{2}{|c|}{$\begin{array}{l}\text { Printed in the United States of America } \\
\text { Available from }\end{array}$}} \\
\hline & \\
\hline \multirow{3}{*}{\multicolumn{2}{|c|}{$\begin{array}{c}\text { National Technical Information Service } \\
\text { United States Department of Commerce } \\
5285 \text { Port Royal Road } \\
\text { Springfield, Virginia } 22161\end{array}$}} \\
\hline & \\
\hline & \\
\hline \multicolumn{2}{|c|}{$\begin{array}{l}\text { NTIS Price Codes } \\
\text { Microfiche A01 }\end{array}$} \\
\hline \multicolumn{2}{|c|}{ Printed Copy } \\
\hline & Price \\
\hline Pages & Codes \\
\hline $001-025$ & $\mathrm{~A} 02$ \\
\hline $026-050$ & $\mathrm{~A} 03$ \\
\hline $051-075$ & A04 \\
\hline $076-100$ & A05 \\
\hline $101-125$ & A06 \\
\hline $126-150$ & A07 \\
\hline $151-175$ & $A 08$ \\
\hline $176-200$ & $A 09$ \\
\hline $201-225$ & A010 \\
\hline $226-250$ & A011 \\
\hline $251-275$ & A012 \\
\hline $276-300$ & A013 \\
\hline
\end{tabular}


ESTIMATION OF AERIAL DEPOSITION AND FOLIAR UPTAKE OF XENOBIOTICS: ASSESSMENT OF CURRENT MODELS
S. O. Link
J. G. Droppo
R. J. Fellows
P. Van Voris
D. A. Cataldo

October 1987

Dr. Craig McFarlane

EPA Project Officer

Prepared for

U. S. Environmental Protection Agency

Corvallis Environmental Research Laboratory

Corvallis, Oregon 97333

under a Related Services Agreement

with the U.S. Department of Energy

Contract DE-AC06-76RLO 1830

Pacific Northwest Laboratory

Richland, Washington 99352 


\section{DISCLAIMER}

The information in this document has been funded wholly or in part by the United States Environmental Protection Agency under Interagency Agreement DW89931928894-01-0 to Pacific Northwest Laboratory, operated for the U.S. Department of Energy by Battelle Memorial Institute. It has been subject to the Agency's peer and administration review, and it has been approved for publication as an EPA document. 


\section{EXECUTIVE SUMMARY}

The primary objective of this report was to review existing mathematical and/or computer simulation models that can be used to estimate xenobiotic deposition to and transport through (both cuticular and stomatal) vegetative surfaces. The secondary objective was to evaluate the potential for coupling the best of those models to the existing UTAB (Uptake, Translocation, Accumulation, and Biodegradation) model to be used for future xenobiotic exposure assessments. Here xenobiotic compounds are defined as airbome contaminants, both organic particulate and gaseous pollutants, that are introduced into the environment by man. In an attempt to simplify a portion of complexity of the question posed, a review of several potential classification systems for organic xenobiotics is also provided.

Specifically this document provides a detailed review of the state-of-the-art models that addressed: 1) aerial deposition of particles and gases to foliage; 2) foliar and cuticular transport, metabolism, and uptake of organic xenobiotics; and 3) stomatal transport of gaseous and volatile organic xenobiotic pollutants. Where detailed information was available, parameters for each model are provided on a chemical by chemical as well as species by species basis. Sufficient detail is provided on each model to assess the potential for adapting or coupling the model to the existing UTAB plant exposure model.

Based solely on the literature evaluation, mathematical linking of these models is possible; however, the immediate utility of this "master" model would be questionable. The inability to adequately link these models at this time results from either a lack of empirical data for specific types of xenobiotics, and/or a lack of detailed understanding of controlling processes in the plant. Specific models are identified and recommendations for further research are provided for each area: 1) wet and dry aerial deposition of xenobiotics; 2) foliar adsorption and cuticular transport of organic xenobiotics; and 3) stomatal transport of gaseous and volatile organic pollutants. 


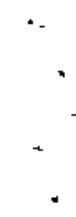




\section{CONTENTS}

EXECUTIVE SUMMARY …........................................................................ iii

INTRODUCTION ..........................................................................................

AERIAL DEPOSITION PROCESSES …..................................................... 2

FOLIAR AND CUTICULAR DEPOSITION PROCESSES ....................... 2

STOMATAL PROCESSES .................................................................... 3

CLASSIFICATION OF XENOBIOTICS CHEMICALS …............................... 5

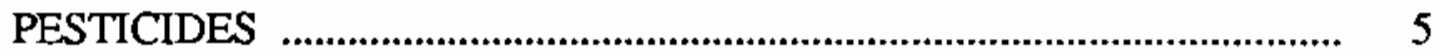

FOSSIL-FUEL RELATED XENOBIOTICS _......................................... 7

AERIAL DEPOSITION MODELS ................................................................. 9

WET DEPOSITION MODELS _.............................................................. 9

DRY DEPOSITION MODELS ................................................................. 11

Gravitional Settling of Large Particles ............................................ 12

Gases and Small Particles ............................................................... 12

FOLIAR PROCESSES AND STRUCTURES ................................................. 21

FOLIAR ABSORPTION

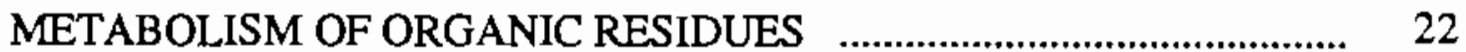

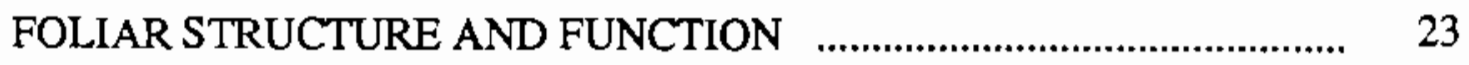

Plant Cuticular Structure ................................................................. 23

Mechanisms and Processes Influencing Foliar

Absorption of Organic Residues ..................................................... 26

CUTICULAR MODELS ................................................................................ 29

SUITABILITY OF AVAILABLE INTEGRATED MODELS $\quad \ldots \ldots \ldots \ldots \ldots . . . . . . \quad 29$

Model of Davis (Davis et al. 1979) ................................................. 29

Model of Price (Price 1982) ........................................................... 30

Model of Hamilton (Hamilton et al. 1982) ......................................... 35

Models of Schönherr and Reiderer (Schönherr 1976 -1982,

Reiderer and Schönherr 1984-1986) ............................................. 38 
STOMATAL OR GAS DIFFUSION MODELS ……...................................... 45

RESISTANCE MODELS …........................................................... 47

Model of O'Dell (O'Dell et al. 1977) ............................................... 47

ENVIRONMENTALLY DRIVEN MODELS ........................................ 51

Model of Kuppers and Schulze (Kuppers and Schulze 1985) .......... 51

Model of Avissar (Avissar et al. 1985) ............................................. 57

Model of Hicks (Hicks et al. 1985) .................................................. 59

ABIOTIC AND BIOTIC FACTORS CONTROLLING STOMATAL



Diffusion of Water Vapor to Infer the

Diffusion of Other Gases ................................................................... 64

Stomatal Parameters ...................................................................... 65

Molecular Diffusivity of Gases in Air ............................................ 65

CONCLUSIONS AND RECOMMENDATIONS _.............................................. 69

AERIAL DEPOSITION MODELS ……................................................. 71

Wet Deposition Models ...................................................................... 71

Dry Deposition Models ................................................................. 72

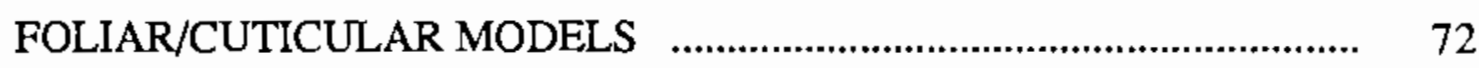

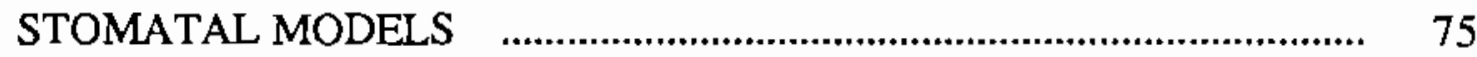

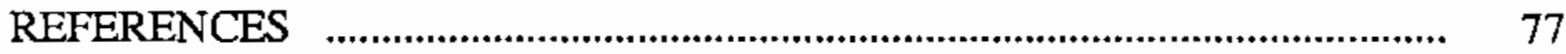




\section{FIGURES}

1 Schematic of Plant Outer Epidermal Cell Wall with Cuticular Membrane .. 24

2 Model of Foliar Uptake According to Hamilton et al. (1982). The Cuticle is Represented by a Lipid Membrane Separating External and Internal (aqueous) Phases. Movement is by Diffusion ............................ 36

3 Schematic Cross Section of a Dicotyledonous Leaf Showing Pollutant Gas Concentration and Resistances (from O'Dell et al. 1977)....................... $\quad 46$

4 Stomatal Resistance as a Function of Stomatal Aperture (Adapted from O'Dell et al. 1977)

5 Test of the Model for the Natural Daily Cource of Climate (Adapted from Kupper and Schulze 1985)

6 Linkage of Source Term, Aerial Deposition, Foliar/Cuticular, and Stomatal Models with the EPA UTAB Model 


\section{TABLES}

1 Classification of Herbicides Based on Chemical Group and Class .............. 6

2 Physicochemical Classification of Fossil-fuel Related Organic Residues. Aromatic Classes and Suitable Representative Compounds are Listed in Order of Increasing Complexity

3 Permeability Coefficients $\left(K_{p}\right)$ of Cuticules and Membranes from Various Organic Compounds, from Davis et al. (1979)

4 2,4-D Permeance Coefficients of Plant Cuticular Membranes P (CM) and Polymer Matrix Membranes P (MX) According to Reiderer and Schönherr (1985)

5 Gravimetric Thickness of the Cuticles (1) used to Extrapolate Holdup Times for the Diffusion of 2,4-D Across Cuticular Membranes [te(CM)] and Polymer Matix Membrane [te(MX)] (taken from Reiderer and Schönherr 1985)

6 Mean Diffusion Coefficients $\left(D^{*}\right)$ for 2,4-D in Plant Cuticular Membranes (CM) and Polymer Matrix Membranes (MX). Adapted from Reiderer and Schönherr (1985)

7 Comparison of Determined and Calculated Permeability Coefficients for the Diffusion of 2,4-D Across Plant Cuticular Membranes. Adapted from Reiderer and Schönherr (1985)

8 Parameters for Equations in the Model of Kuppers and Schulze (1985) ......

9 Values of $b$ and $S$ for Functions of Stomatal Response to

Environmental Factors

10 Stomatal Density, Pore Length, and Pore Width on the Axial (lower) Side of Leaves, with the Minimal Stomatal Diffusion Resistance for CO2 (computed from one side of leaf). Adapted from Larcher (1980)

11 Characteristics of Various Air Pollutants. (From Tingey and Taylor 1982) 


\section{INTRODUCTION}

Airborne contaminants, like organic particulate and gaseous pollutants, can be transported over long distances and interact with a broad range of vegetative surfaces. The question posed is whether sufficient data exist to understand and define those processes controlling atmospheric transport, canopy interception, foliar transport, and the subsequent fate of xenobiotics within the plant. The principal objective of this assessment was to review existing mathematical and/or computer simulation models that are used to estimate the following:

1. aerial deposition of xenobiotics to plants,

2. foliar/cuticular transport of organic xenobiotics, and

3. stomatal transport of gases and volatile organic xenobiotics.

Given that objective, our efforts were directed towards those models that were designed to address transport and fate of xenobiotics within a single leaf rather than at the crop canopy spatial scale.

The second objective was to provide sufficient detail on those models to determine the potential for adapting or coupling those models to the existing UTAB (Uptake, Translocation, Accumulation, and Biodegradation) plant exposure model (McFarlane 1986). The UTAB model for the simultaneous transport of water and a trace organic solute in a plant is currently being developed by the U.S. Environmental Protection Agency's (EPA) Corvallis Environmental Research Laboratory (CERL) in conjunction with scientists at Oregon State University. The model will be used to examine the characteristics of uptake and accumulation of organic chemicals in a single leaf/stem/root representation of soybean (Glycine max L.) plant under conditions of constant transpiration allowing for passive as well as active uptake of the solute. The extent to which the present UTAB model can be interfaced with existing aerial transport/canopy deposition, and foliar transport models (both cuticular and stomatal) will depend heavily on the chemical stability, chemical nature, and particularly the biological behavior of the individual compound or class of compound of concern. 


\section{AERIAL DEPOSITION PROCESSES}

Deposition of airborne xenobiotic materials on plant surfaces may occur as the result of a number of different processes. These atmospheric processes may be broadly divided into two major groups, wet and dry deposition. Wet deposition is defined as air-to-surface transfer by precipitation; dry deposition is, therefore, the transfer by nonprecipitation processes. Wet deposition occurs as a direct impaction of the liquid or solid precipitation element on the foliar surfaces. Dry deposition involves processes such as impaction, sorption, and diffusion which result in the transfer of airborne xenobiotic materials.

In general, our ability to model and predict the airborne behavior and fate of contaminants will be dependent on our understanding of specific controlling processes. Atmospheric transport represents primarily a series of physical processes, for which much relevant information is already known. However, there are specific areas of uncertainty relating to the behavior of organic compounds and gases both in the cloud layer as well as at the boundary layer of the plant. These include the fraction of a compound in the gaseous versus condensed state, and the extent to which a compound undergoes chemical alteration or sorption to airborne particles prior to deposition. The actual deposition of airborne constituents to foliar surfaces will be similarly governed by a series of physical processes which control the rate of transfer of components from the atmosphere, through the boundary layer of leaves, and onto foliar surfaces. Again, the rates of deposition for individual xenobiotic compounds will be dependent on whether they are in gaseous, particulate or adsorbed form on particles or droplets.

\section{FOLIAR DEPOSITION PROCESSES}

The extent of cuticular penetration/foliar absorption and subsequent fate of organic contaminants once deposited to foliar surfaces represents the weakest component with respect to developing a reliable transport/absorption model, and its eventual coupling 
with the existing UTAB model. While there are a number of uncertainties relating to the actual physical and thermodynamic mechanisms controlling the deposition of contaminants to foliar surfaces, these parameters can be estimated based on the behavior of reactive and nonreactive gaseous species $\left(\mathrm{H}_{2} \mathrm{O}, \mathrm{SO}_{2}, \mathrm{H}_{2} \mathrm{~S}, \mathrm{NO}_{\mathbf{x}}, \mathrm{CO}_{2}\right.$, etc $)$. The crucial problem is to address and resolve those parameters and processes which control the extent of retention and absorption of organic contaminants deposited to foliar surfaces. These will not only be a function of the chemical characteristics of the organic contaminant, but also the structure and chemical characteristics of the epidermal and cuticular tissues of the individual plant species. The latter represent the primary barriers to entry of xenobiotics into the symplast and linkage of the atmospheric transport model to the existing UTAB plant model.

\section{STOMATAL PROCESSES}

Approaches to describing the processes which address gaseous diffusion through the stomates generally fall into two classes:

1. models which focus on the resistance catena concept using Fick's law; and

2. models which focus on abiotic and biotic factors which influence stomatal resistance or conductance (resistance is the reciprocal of conductance).

Fick's law type models attempt to locate discrete resistance elements in the catena, predict gaseous concentrations at various points from the outside to the inside of the leaf, and flux rates between the resistance elements. The second class of stomatal diffusion models attempt to parameterize the relationship between the resistance elements and factors which influence thein. These models generally lead to the prediction of gaseous concentrations and flux rates at various points in the catena in real time as a function of 
abiotic or biotic variables. The review and recommendations for further research in the area of stomatal modeling will focus on the merits of the best of each type of model. 


\section{CLASSIFICATIONS OF XENOBIOTICS CHEMICALS}

A myriad of organic contaminants or pollutants (xenobiotics) contained within the biosphere can be absorbed by terrestrial plants. Plants therefore represent an indirect route for transfer of potentially toxic materials to man. These organic contaminants can include a variety of pesticides, industrial emissions, combustion products and waste by-products. However, unlike the situation which exists with inorganic pollutants where distinct pattems of bioaccumulation are observed, many organic contaminants are subject to chemical and biological degradation, and chemical modification once accumulated by plants. This change in chemical form makes estimation of foliar absorption and fate extremely difficult.

Given the above mentioned limitation some form of classification, by chemical type, must be established. For convenience, and because of the limited data bases available, two major categories of organic xenobiotics and their functional chemical classes will be addressed. These categories include pesticides and fossil fuel related components, which directly or indirectly comprise the majority of airbome organic emissions.

\section{PESTICIDES}

This category of xenobiotics, including foliarly applied herbicides and insecticides, provides the largest data base available for establishing the extent of foliar absorption and eventual fate of organic compounds. A wide variety of chemical compounds are classified as herbicides (Table 1 ). These types of classifications are readily compiled froin texts and review articles on herbicide behavior (Hartley and Kidd 1983; Crafts and Robbins 1962; Ashton and Crafts 1981; Beste 1983). This by no means is a complete classification, and many compounds exist which do not fall into the major listed groups. However, the important point is that chemicals selected as herbicides exhibit certain characteristics which allow for some degree of control over penetration, mobility, mode of action, and specificity. These same characteristics are useful in parameterizing, 
TABLE 1. Classification of Herbicides Based on Chemical Group and Class

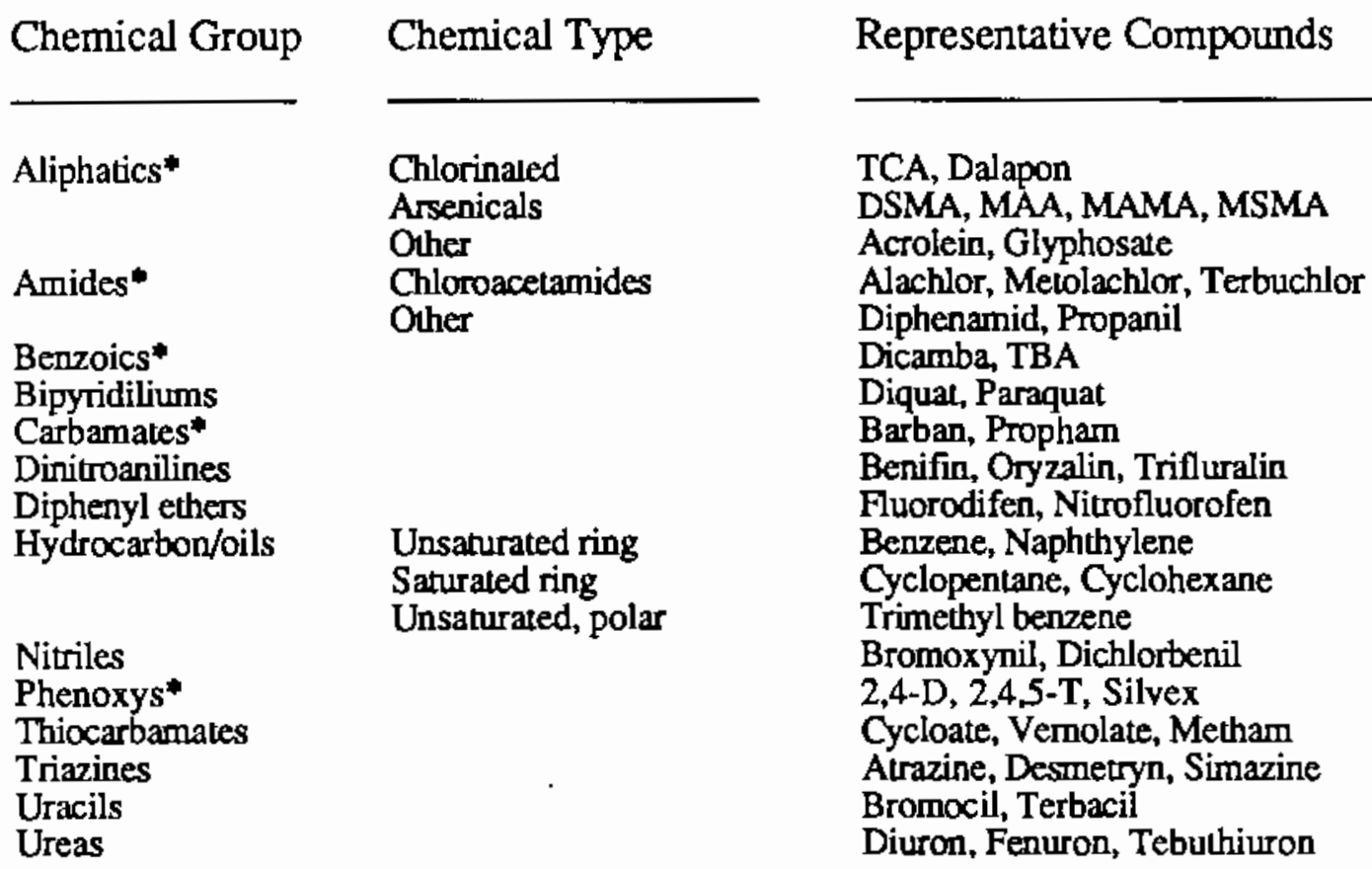

* Indicates the presence of compounds within each class which are foliar absorbed and translocated.

modifying, and providing the necessary data to link existing models. Of the chemical groups listed in Table 1 (note *), the polar aliphatics, amides, benzoics, carbamates and phenoxys are known to be readily translocated via the phloem following foliar absorption. The other groups, while able to be absorbed from foliar surfaces, will exert only a localized effect since they are generally only xylem mobile. For our purposes, and the need to understand the behavior of a variety of chemical classes, it is worth noting that this lack of mobility is particularly true for many of the oils and aromatic hydrocarbons employed as herbicides and/or used as aducts.

Substantially less data are available on the behavior of insecticide type compounds in plants. In general, insecticides are designed to be respiratory or cholinesterase inhibitors. They consist of relatively complex inolecules having a range of active functional groups including phosphonates, thiophosphates, nitriles, organo-cyanides, and in many cases contain one or more chlorine residues. While many of these compounds are prone to 
relatively rapid hydrolysis, they can have persistent residues. These residues frequently contain chlorinated aromatic rings, ethers and esters which are resistant to metabolic degradation. Although unsubstantiated, it would be expected that in their hydrophilic state (charged/polar) they may be mobile in plants following hydrolysis and partial degradation. Once partially degraded, their residues may be more hydrophobic (lipid-soluble) and accumulate at the site of deposition.

\section{FOSSIL-FUEL RELATED XENOBIOTICS}

Organic residues derived from fossil fuels represent the major source of feed stocks for the production of organic chemical based products ranging from pesticides, to fuel products, and to plastics. The enormous number and types of organic residues comprising this group make prediction of their foliar behavior extremely difficult. However, a rather straightforward classification scheme was devised by the Department of Energy (DOE), Office of Health and Environmental Research (OHER), to provide an approach for systematic study of a wide range of organic constituents using representative compound classes (Zachara et al. 1984). This classification scheme, like that for herbicides, is based on the physicochemical properties of organic residues. These are shown in Table 2. Eight classes of compounds were selected based on specific criteria. These criteria included: 1 ) the chemical composition of a wide variety of liquid wastes; 2) potential environmental concentrations for individual classes; 3) water solubility; and 4) chemical complexity. Based on these criteria, eight classes of aromatic compounds were selected as candidates for integrated research efforts. These included amines, neutral aromatic N-Heterocycles, basic aromatic N-Heterocycles, phenols, nitroaromatics, thiophenes, neutral aromatic hydrocarbons, and furans. Within each class, specific representative compounds were selected for environmental evaluation; these are listed in increasing order of chemical substitution and complexity. 
TABLE 2. Physicochemical Classification of Fossil-fuel Related Organic Residues. Aromatic classes and suitable representative compounds are listed in order of increasing complexity.

Compound
Class

Amines

Basic Aromatic

$\mathrm{N}$-Heterocycles

Phenols

Neutral Aromatic

N-Heterocycles

Nitroaromatics

Thiophenes

Neutral Aromatic Hydrocarbons

Furans
Representative Compounds

Aniline,1-Aminonaphthalene,1-Aminoanthracene, 2-Aminobenzo(a)anthracene

Pyridine, Quinoline, Acridine, Benzo(a)acridine

Phenol, 1-Naphthol, 1-Hydroxyanthracene, 2-Hydroxybenxo(a)anthracene

Indole, Carbazole, Benzo(c) carbazole

Nitrobenzene, 1-Nitronaphthalene, 1-Nitroanthracene, 2-Nitrobenzo(a)anthracene

Benzo(b)thiophene, Dibenzo(b,d)thiophene, Benzo(b)naphtho(1,2-d)thiophene

Naphthalene, Anthracene, Benzo(a)anthracene

Benzo(b)furan, Dibenzo(b,d)furan, Benzo(b)naphtho( 1,2$)$ furan

Although the selection criteria for the compounds shown in Table 2 was based on problems associated with soil and groundwater transport of organic residues, the classification is suitable for establishing a basis from which the foliar absorption of specific organic compounds can be established. A review article by Sims and Overcash (1983) describes the soil and plant behavior of polynuclear aromatics, and serves to demonstrate the overall complexity of the problem. Unfortunately, little foliar absorption data are available for these or other organic residues. Data which are available provide an incomplete picture of those processes that affect foliar absorption; the latter being critical to both the development and parameterization of integrated interception/absorption and transport models. Key to the present discussions are 1) the ability of organic residues to be absorbed through foliage, 2) whether the organic residue are phloem mobile and therefore able to be redistributed within the plant, and 3) the extent to which organic residues are metabolized and/or chemically modified. 


\section{AERIAL DEPOSITION MODELS}

Atmospheric processes controlling xenobiotic transport and deposition to foliar surfaces may be broadly divided into two major groups, wet and dry deposition. Wet and dry deposition are quite different in duration and magnitude. Wet deposition involves the removal of xenobiotic materials over relatively short time periods from what can be a considerable depth of the atmosphere. Dry deposition involves the deposition of xenobiotic materials over longer time periods onto plant surfaces and is a function of the air concentrations immediately over the receptor surfaces. Typically, wet deposition has much greater rates of removal than dry deposition. However, dry deposition occurs over longer time periods and can have higher cumulative deposition amounts. Atmospheric processes such as dew, fog, and riming also can result in significant rates of deposition of xenobiotic materials. Thus, modeling deposition of xenobiotic materials is divided into two distinct scenarios: 1) intermittent inputs of xenobiotic materials (wet deposition) and, 2) the more continuous input of xenobiotic materials (dry deposition).

\section{WET DEPOSITION MODELS}

The modeling efforts for wet deposition generally combine rainout (within cloud scavenging) and washout (below cloud scavenging). Hanna et al. (1982) provides a review of simple modeling methods that could be used to estimate the deposition rates of xenobiotic materials. These models fall into two major groups; those based on a scavenging coefficient and those based on a washout ratio. An approximate relationship relating these two parameters is provided in Hosker (1980). The choice of which model to use is relatively arbitrary. The scavenging coefficient approach allows detailed case study computations when data on cloud dimensions, height and droplet size spectrum are known; the washout ratio is best suited to longer-term estimates.

More complex precipitation scavenging computer models such as MPADD (Hales et al. 1983) and PLUVIUS (Easter and Hales 1984) provide the user with the capability to 
model case studies of the atmospheric removal of various xenobiotic materials. These models are suitable for case-study computations of potential deposition rates in situations where the simpler models given in Hanna et al. (1982) are inadequate. Any wet deposition model will need to include both in-cloud particle scavenging and gas solubility. Scott (1982) provides a discussion of particle scavenging processes while Levine and Schwartz (1982) discuss gas scavenging processes. Thorp and Scott (1982) provide useful data summaries for characterizing storm parameters needed for modeling wet deposition.

The PLUVIUS code, a one-dimensional reactive-storm model, allows simulation of a variety of storm types. The in-storm behavior of xenobiotic materials can be characterized as they flow through, react within, are scavenged, and carried downward to the surface below. The PLUVIUS model is designed to handle both aerosol and gaseous xenobiotic materials. The treatment of precipitation-formation processes and reactive scavenging occurs in a highly parameterized fashion. Pollutants may exist in solid, aqueous, or gaseous phase within the cloud. Using a steady-state assumption, PLUVIUS may be used as a two-dimensional model.

Intense short-term deposition of xenobiotic materials may occur under certain special atmospheric conditions. Impaction by fog droplets is an example of such a process and dew formation is another. Though potentially very important, only limited data are available on the magnitude of deposition for such events. A number of studies are under way to address this lack of adequate data. Assuming that data are available, custom models would have to be developed to estimate the frequency and order of magnitude of deposition of xenobiotic materials under these special atmospheric conditions.

For example, a recent study of the chemical composition of dew was conducted in a urban area (Mulawa et al. 1986). The results showed that natural dew is similar to rainwater except that the dew has much higher concentrations of $\mathrm{Ca}^{2+}$ and $\mathrm{Cl}^{-}$and much lower acidity. In a comparison of deposition rates to artificially generated dew and a dry 
surface, they found that the presence of dew enhances both the retention of dry deposited particles and the absorption of water soluble gases. Deposition velocities are reported for sixteen chemical species -- these data, and similar data from other studies, could provide a basis for modeling the short-term elevated deposition of xenobiotic materials.

\section{DRY DEPOSITION MODELS}

Modeling dry deposition rates of airborne xenobiotic materials onto plant components is usually viewed as a series of processes, any combination of which may be controlling the deposition rate under a given set of conditions. When surface and/or internal processes result in rapid deposition, then the atmospheric delivery rates to the surface can limit the deposition rate. However, if surface uptake rates are sufficiently slow, atmospheric delivery rates do not limit the deposition rate.

A number of studies of dry deposition of radioactive and non-radioactive materials have been conducted. Reviews of these studies are provided by Hosker and Lindberg (1982) and Sehmel (1980).

Which processes are limiting the deposition rate depends on both the ambient conditions and the properties of the xenobiotic material of interest. For example, gaseous and particulate materials will deposit in different ways because of different surface deposition processes. Chemical and physical properties of each xenobiotic material are needed to model deposition rates.

The ambient concentration (or air-receptor concentration gradient if the concentration is nonzero within the receptor) is the single most important factor in determining potential deposition rates in the ambient concentrations. Most current models for deposition assume that the atmospheric deposition rate is directly proportional to the ambient air concentration (gradient). To allow for materials whose deposition rate is clearly controlled by plant processes (i.e., stomatal openings, to be 
discussed later), the constant for proportionality $\left(\mathrm{V}_{\mathrm{d}}\right.$, deposition velocity) varies with changes in the receptor surface.

The exposure of plant materials to ambient atmospheric concentrations under nonprecipitation conditions can result in the greatest long-term exposures. A model for the dry deposition of xenobiotic materials must account for the properties of the xenobiotic materials, atmospheric processes, and receptor properties. Dry deposition models for gravitational settling of large particles and gases and small particles are discussed below.

\section{Gravitational Settling of Large Particles}

Modeling the deposition rate resulting from gravitational settling of larger particles (greater than $5 \mu \mathrm{m}$ ) is straightforward if the appropriate settling velocity for the material of interest is known. The settling velocity, $\mathrm{V}_{s}$, of spherically shaped particles with radii, $\mathrm{r}$, less than 10 to $30 \mu \mathrm{m}$ is given by Stokes' law:

$$
\mathrm{V}_{\mathrm{s}}=2 \mathrm{r}^{2} \mathrm{ga} / 9 \mathrm{~m}
$$

where $\mathrm{g}$ is gravitational constant, $\mathrm{a}$ is the particle density, and $\mathrm{m}$ is the dynamic viscosity of air. The modeling of xenobiotic deposition of larger particles needs to use a modified form of Stokes' law, or use a graphical solution such as given by Van der Hoven (1968). In addition, nonspherical shapes of the xenobiotic particles can be approximated by using dynamical shape factors such as given by Hanna et al. (1982) based on Chamberlain (1975).

\section{Gases and Small Particles}

Dry deposition of gases and particles with less than about $10 \mu \mathrm{m}$ radii can be treated in a manner similar to that presented above in terms of their movement in the 
atmosphere. The assumption is made in the deposition models that gases and small particles move passively with air motions.

The concept of a resistance approach is a useful framework for both discussion and modeling of the applicable dry deposition processes. The total resistance, $\mathrm{r}$ total, for dry deposition of a material from some height in the atmosphere is typically given in an equation such as discussed by Bache (1986):

$$
r_{\text {total }}=r_{a}+r_{c}+r_{s}
$$

where $r_{a}$ is the atmospheric resistance from the reference height down to the vicinity of the canopy elements, $r_{c}$ is the remaining atmospheric resistance for movement of the depositing material in the air immediately over the canopy receptor surfaces, and $r_{S}$ is the remaining bulk surface resistance of the canopy. The total deposition resistance is the inverse of deposition velocity, $V_{d}$,

$$
\mathrm{r}_{\text {total }}=1 / \mathrm{V}_{\mathrm{d}}
$$

The processes for gases and small particles are normally assumed to be the same for $\mathrm{r}_{\mathrm{a}}$. The gaseous and particulate deposition processes will be quite different for the $r_{c}$ and $r_{S}$ terms.

Using such a resistance model for dry deposition requires that the deposition resistance be computed for each of these stages in the deposition process. In general, the $r_{a}$ and $r_{c}$ are better understood and characterized than $r_{S}$. 
The atmospheric resistance may be computed by analogy with concurrent surface fluxes of other materials/properties. A popular analogy is with surface momentum flux, giving the following expression for the atmospheric momentum resistance, $r_{m}$, under neutral atmospheric conditions,

$$
\mathrm{r}_{\mathrm{m}}=\mathrm{u}^{* 2} / \overline{\mathrm{u}}
$$

Under other than neutral conditions, the influence of atmospheric stability needs to be included in this computation. Businger et al. (1974) provide empirical relationships for stability effects on micrometeorological parameters. The momentum resistance is related to the atmospheric resistance of an atmospheric constituent by

$$
r_{\mathrm{a}}=\mathrm{e} \mathrm{r}_{\mathrm{m}}
$$

The factor, $\mathrm{e}$, is the correction for any difference in the manner in which the constituent is transported compared to momentum. Although the momentum analogy $(e=1.0)$ is popular in deposition models, the dry deposition of ozone was shown by Droppo (1985) to be more analogous to surface heat flux. Empirical micrometeorological relationships from similarity theory provide a basis for computing atmospheric resistances based on surface heat flux analogies (Droppo et al. 1986). The choice between using momentum or sensible heat analogy can result in large differences in the atmospheric resistances factors, and is particularly important in studies where resistance terms are computed as residuals. For the modeling of xenobiotic materials, the assumption of an analogy with sensible heat flux is recommended.

Modeling atmospheric deposition onto vegetation canopies is a difficult and complex task. The structure of vegetation canopies can make the model for $\mathrm{r}_{\mathrm{a}}$ and $\mathrm{r}_{\mathrm{c}}$ over vegetation canopies quite complex. In addition, the models for the $r_{s}$ term need to include a multitude of components (i.e., stomata/mesophyll, cuticle, soil, water surfaces). 
The deposition model has to account for the variation of these components in both space and time. Particularly challenging is the modeling of the effects of the interdependent vertical variations of plant density parameters, temperature, moisture, solar/net radiation energy loads, wind speeds, and various turbulence parameters.

The theory and field results for particulate deposition rates even on relatively "simple" collector plates was shown by Garland (1983) to have the same trends, but quite different magnitudes. Garland attributes the under prediction to perhaps being the result of inadequate modeling of the effect of the geometry of the collector plate. Likewise, but perhaps unrelated, the theory for dry deposition on larger plant canopies consistently gives lower fluxes than researchers have found with field measurements. Slinn (1983) suggests the field measurements may be in error, but the question remains largely unresolved at this point.

So, if the theory and measurements do not agree, how can one model the deposition of xenobiotic materials and have any confidence in the results? For very high canopies (i.e., forests) the modeling results are going to be uncertain. For simple lower canopies, current models should provide useful estimates of deposition rates.

A particularly useful data set in modeling the $r_{a}$ and and $r_{S}$ term for particulate matter is from the wind tunnel tests of Sehmel and Hodgen (1978). The empirical curves proposed by Sehmel and Hodgen have been used in a number of modeling efforts (i.e., Doran and Horst 1985; Droppo et al. 1986). Recently, Schack et al. (1985) developed an alternative correlation for computing deposition over competely rough surfaces based on literature data.

The importance of atmospheric turbulence in deposition rate depends on whether the vertical rate of transport of a material in the atmosphere is greater or less than the rate of uptake/destruction at the receptor surface. As a general rule, slowly depositing materials are limited by the surface processes and rapidly depositing materials are limited by the atmospheric processes. The atmospheric processes define a maximum rate for dry 
deposition. This deposition rate has a strong diurnal trend; high during daytime and low during nighttime conditions.

In situations where atmospheric processes are limiting the deposition rate, a depletion of air concentrations will occur in the surface layer as a result of dry deposition. Even for carbon dioxide uptake, whose uptake is the result of physiological plant processes, atmospheric turbulence can be limiting (Lemon 1963).

Horst (1984) developed a surface depletion model to account for decreased dry deposition rates resulting from the near-surface depletion of contaminant concentrations. Horst (1984) provides approximate relationships for use in applied atmospheric dispersion models. An alternative approach, adopted by Droppo et al. (1986), involves computing the total micrometeorological resistance to fluxes from 10 meters height over the surface. The latter approach accounts for the surface depletion effects in terms of a greater atmospheric resistance value. Regardless of which modeling approach is selected, significant reduction in deposition rates of almost all xenohiotic materials are expected under nighttime conditions compared to daytime conditions.

A measurement approach based on computing the change in concentration ratio of a depositing to a non-depositing chemical species between the source and downwind site has been demonstrated by Doran an Horst (1985). The duel-tracer approach has been expanded to larger scales using ambient monitoring data by Friedlander et al. (1986).

Air quality models often simplify dry deposition by assuming a single deposition velocity for all situations. The deposition velocity is defined as the ratio of flux of a pollutant to the ambient air concentration at some reference height over the surface. Although this approach may provide reasonable average values for an ensemble of conditions, the fluxes for particular conditions may be quite inaccurate.

Although models available for computing atmospheric dry deposition rates are mainly components of air quality models, a few models have been developed that stress 
the dry deposition computation. A version of the EPA PAL model is available with an improved dry deposition computation model (Horst 1984). Hicks et al. (1985) provide a comprehensive model for translating observed air concentrations into dry deposition rates. Also a detailed atmospheric dry deposition model such as developed by Van Voris et al. (1985) and Droppo (1985) provides for computation of dry deposition rates of xenobiotic materials for special sets of conditions over various surfaces.

Modeling efforts have been mainly directed toward computation of momentum, carbon dioxide, and water vapor fluxes over vegetative canopies (Cionco 1985; Jarvis et al. 1985). By assuming an analogy between these fluxes and xenobiotic materials, these models can provide a framework for a xenobiotic deposition model.

The modeling of the atmospheric deposition processes within plant canopies is a complex and difficult problem. Lewellen and Sheng (1982) proposed a second-order closure model for transport/deposition in canopies. Lewellen and Sheng's model predictions were in agreement with data for deposition underneath a flat plate (Lane and Stukel 1978) and over a smooth brass plate (Sehmel 1973).

Detailed canopy deposition models for gaseous material (Bache 1986) and particulate material (Wiman 1985; Wiman and Agren 1986) have been proposed. These models generally involve a solution of convective-diffusion equations for transport from the air to the plant elements. Although a full implementation of these models may not be required for the computation of xenobiotic materials, these models do provide a reasonable basis for formulating a model that would meet the need to compute the inputs from atmospheric deposition.

Bache (1986) points out that there have been two major approaches to modeling the resistance terms for dry deposition to a vegetation canopy. The first is the 'external' description of the vertical flux over the canopy linked to an apparent or virtual sink/source within the canopy (Chamberlain 1966). The second approach, an 'internal' description, models the local transport processes within the canopy to yield bulk 
exchange parameters (Thom 1975). Bache (1986) addresses the fundamental differences between these two approaches and demonstrates how the simple adding of resistances in parallel may not always be an appropriate means of combining these approaches.

Bache (1986) proposes that under conditions of high surface resistance, the bulk deposition velocity, $v_{d}$, at the top of the canopy approaches a limit defined by

$$
v_{d}=v_{g} L_{p}\left(1-U v_{g} L_{p} / u^{*}\right)
$$

where $v_{g}$ is the local deposition rate, $L_{p}$ the effective foliage area, $u^{*}$ friction velocity, and $U$ a structure coefficient. From this, a criterion is proposed for defining the conditions for which resistances may be added in parallel. Under conditions of zero surface resistance, an expression similar to Equation 6 is given. A general expression is formulated for the sublayer Stanton number $\left(r=\mathrm{u}^{*}\right)$ at the extremes of high and low canopy resistances. These results show that there is not a clear separation of the terms $r_{c}+r_{s}$ and the $r_{a}$ term under conditions of high surface resistances.

The importance of having an explicit model of the atmospheric component of the dry deposition of xenobiotic materials for plants is linked to the processes at and within the plants that are discussed in the following sections. In general, models for materials having relatively large deposition velocities should include a detailed atmospheric component, whereby models for materials with small deposition velocities rates can use a less detailed atmospheric component. Materials with very small deposition velocities will not require an atmospheric component.

Major changes in the dry deposition rates will occur with changes in ambient weather conditions. Potentially large diumal changes in deposition rates can occur between daytime well-mixed-conditions and nighttime poorly mixed conditions. The 
greater ventilation of a canopy under windy conditions compared to near-calm conditions can result in greater deposition rates. Seasonal changes in dry deposition rates can be expected as the ambient weather conditions change and the character and properties of the underlying surfaces change. 



\section{FOLIAR PROCESSES AND STRUCTURES}

The following discussion attempts to address the essential parameters and components required to describe and quantitate the foliar transport and absorption of organic xenobiotics. The ultimate goal is to provide sufficient data to permit a linkage of the necessary submodels to describe the potential fate and impact of a range of organic contaminants.

\section{FOLIAR ABSORPTION}

Foliar absorption is known to occur for both inorganic ions and organic compounds. Therefore it can be assumed that the hydrophobic and hydrophilic structures of leaves will permit entry, to some extent, of both polar and nonpolar organic residues. For example, the effects of foliarly applied organic residues have been more or less apparent for nearly 100 years. Mirande (1910) observed that when coal tar was applied to streets for dust control, adjacent plantings showed severe foliar damage. This damage was latter attributed to anthracene and acridine associated with the coal tar, and was alleviated by use of light oils. Similarly, an early report of Crafts and Rieber (1948) described the usefulness of oils as herbicides, and particularly the fact that higher boiling fractions are most toxic. Aromatic hydrocarbons are most damaging, and toxicity increases with imcreasing substitution. In addition, Currier and Peoples (1954) showed that damage from hydrocarbons resulted from disruption of the physical structure of cell membranes.

More recent foliar absorption studies with individual compounds, although limited, demonstrate the permeability of the foliar surface to a range of compound types. Edwards et al. (1982) found that anthracene volatilized from solutions within enclosed chambers was adsorbed to and absorbed from foliar surfaces of soybean. Sixty-nine percent of the airborne dose was found in or on the leaves, while $1.5 \%$ was translocated to the root. In comparison, data of Isensee and Jones (1971) indicate no translocation of 
2,4-dichlorophenol, 2,7-dichlorodibenzo-p-dioxin, 2,3,7,8-tetrachlorodibenzo-p-dioxin or other such compounds after 21 days following application to leaves of soybean and oats. The data for the aromatic hydrocarbons associated with oils and the limited individual compounds, along with those for foliar absorbed and translocated herbicides (see Table 1, on page 6) indicate that a wide range of chemical compounds can be absorbed, if not translocated, following foliar application. The problem is how to systematically establish the functional relationship between chemical characteristics of a compound and its propensity for foliar absorption and subsequent transport; this may require that important compound ciasses be identified and evaluated.

\section{METABOLISM OF ORGANIC RESIDUES}

The ability to model the absorption and chemical fate of organic residues in plants is further complicated by the extent of modification and/or metabolism at the site of entry to the symplast (leaf). While a substantial database exists on the metabolism and fate of herbicides and other individual compounds, these will only be briefly addressed to demonstrate the range of potential interactions. Chlomethoxynil, a nitrile class of herbicide, is prone to conjugation at the nitro group (Niki et al. 1976); this can involve simple conjugation to form amino and diamino derivatives, or the formation of immobile conjugates with lipids and lignin. Anthracene absorbed by roots (Edwards 1986) was shown to be chemically altered in roots $91 \%$ of the time and leaves $99 \%$ of the time in bushbean. These modified forms were shown to be as polar metabolites (29\%), nonpolar metabolites (18\%), and non-extractable incorporated forms (53\%). Similarly, pentachlorophenol is modified in a variety of ways in plants. Casterline et al. (1985) found the rapid formation of methylated derivatives, tetrachlorophenol and anisoles from pentachlorophenal; however, no conjugated forms were identified. Studies with structurally simpler organic residues (Cataldo et al. 1986) demonstrate options for other types of metabolic fate. Phenol and aniline were found to be rapidly oxidized and

degraded to $\mathrm{CO}_{2}$, and metabolites. A small fraction of the aniline was found to be insoluble and conjugated. In comparison, $95 \%$ of the quinoline was recovered from root 
and leaf tissue in the parent form with little oxidative decomposition or metabolism evident. Of the quinoline that was metabolized (5\%), reactions such as hydroxylation, methylation, hydrogenation, and ring opening were evident.

\section{FOLIAR STRUCTURE AND FUNCTION}

\section{Plant Cuticular Structure}

The outer wall of plant epidermal cells can be distinguished from all other plant cell walls by the presence of a thin continuous layer of predominantly lipid material deposited on its outermost surface. The presence of this outer layer, or cuticle, has been known for almost 150 years, and has been studied extensively. The structure of the cuticle is heterogeneous varying not only between species, but even within the same species depending on the environment in which the plant grows (Baker 1980; Holloway 1982).

The cuticle, or cuticular membrane (CM), may contain several layers each distinct in location and chemical composition (Figure 1). The primary cuticle which comprises the outermost layers may have an external "epicuticular" layer of wax beneath which will lie the cuticularized layer (Esau 1965). The matrix of this cuticularized layer may appear uniform through an electron microscope or it may consist of several distinct lamellae of varying thicknesses when observed in the light microscope (Holloway 1982). The primary cuticle can at times form peg-like extensions down into the secondary layer at the junctions between epidermal cells. It is believed that these extensions may serve to anchor the primary cuticle onto the surface.

The secondary cuticle lying below may be referred to as the cuticularized layer of the cell wall (Hallum 1982). This layer has been reported to also include part of the epidermal cell wall, from the apparent presence of cellulosic microfibrils. These may form an extensive reticulate network in some species within the lower regions of this layer (Holloway 1982). The fibrils have been proposed to provide a possible hydrophilic 


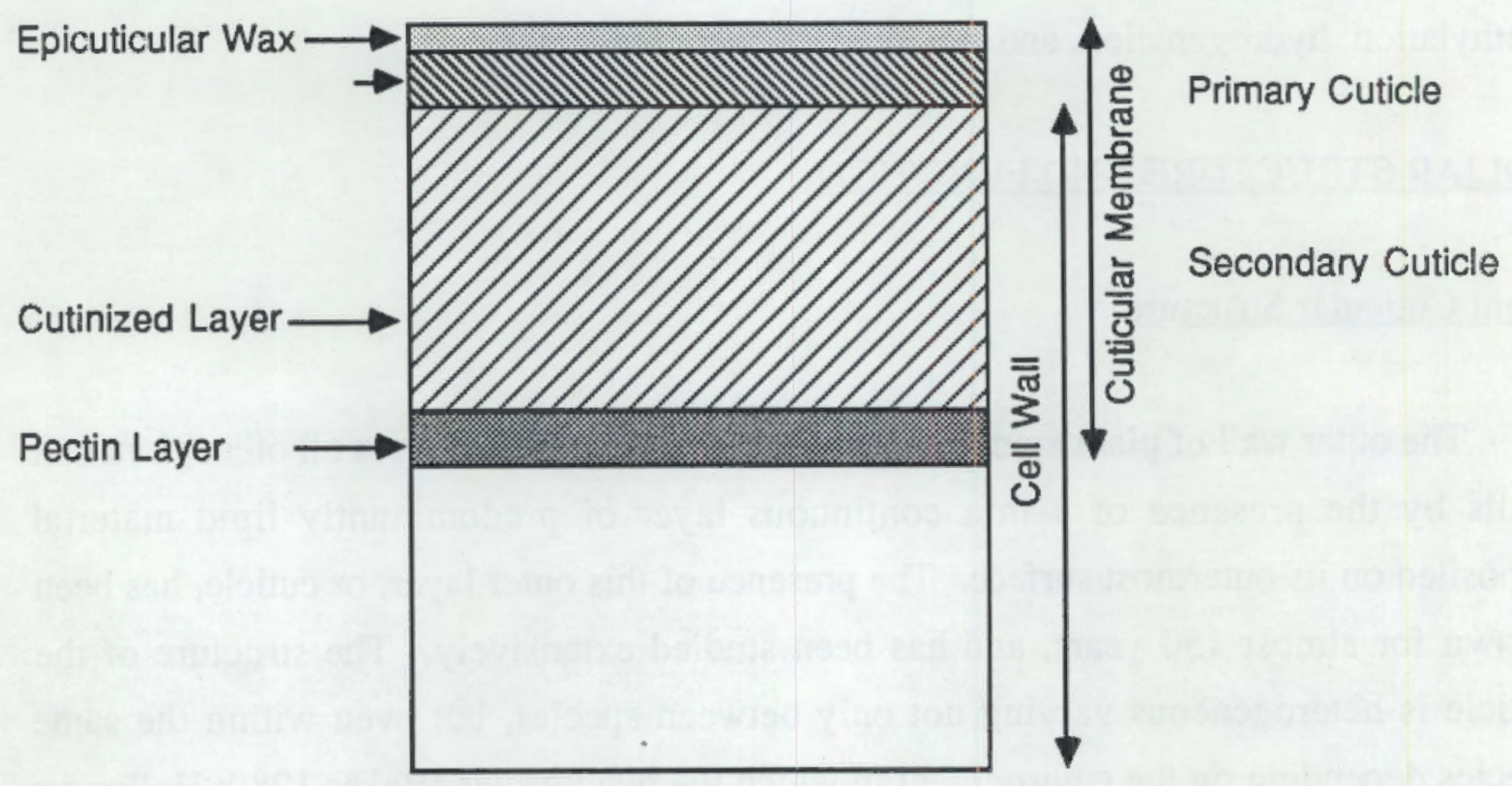

FIGURE 1. Schematic of Plant Outer Epidermal Cell Wall with Cuticular Membrane

pathway extending from the aqueous apoplast in proximity to the external surface of the cuticle (Hoch 1979). Evidence for the cellulosic nature of these microfibrils in the secondary cuticle is based primarily on histochemical studies on the light and electron microscopic level (Wattendorff and Holloway 1980).

Below the reticulate region of the cuticularized portion of the cell wall there may exist a layer of pectin-like material. Evidence for this "pectin layer" comes from histochemical reactions on the light microscope level using ruthenium red. This layer however, has not been observed with the electron microscope (Chafe and Wardrop 1972). The pectin layer has not been observed in all species and no potential functions have been proposed. 
Transcuticular pores, or ectodesmata have also been reported in the literature (Lambertz 1954 and Schnepf 1959 in Hallum 1982). Those pores which appear as peg-like extensions into the cuticle (not completely penetrating) have only been demonstrated using Gilson fixative, a mercury based solution. Schönherr and Bukovac (1970) have since shown the projections to be mercurous precipitates following the pattern of mercuric chloride penetration through the cuticle. Ectodesmata are, therefore, most likely fixation artifacts, and do not exist as a potential pathway through the cuticle.

Two specific types of lipid materials are characteristic of the cuticular membrane: insoluble polymeric cutins which form the framework (matrix) of the membrane, and soluble waxes, either deposited on the surface as epicuticular wax, or embedded within the matrix (Baker 1982). The insoluble polymeric cutin is composed predominantly of interesterified hydroxycarboxylic acids derived from the $\mathrm{C}_{16}$ or $\mathrm{C}_{18}$ family of acids. The cutin polymers may be primarily linear or extensively cross-linked through the secondary hydroxyl groups of the monomers (Deas and Holloway 1977).

The outermost layer, that of the epicuticular wax, may be up to several millimeters thick in some tropical species. The wax can be amorphous in form, or posses a definite crystalline or semi-crystalline structure. These outer wax structures may be in the form of plates, tubes, ribbons, rods, filaments, or dendrites. Their appearance is not only species dependent, but also ontogenetically and environmentally variable (Baker 1982). Chemically the epicuticular wax may be comprised of pentacyclic triterpenoids (ursolic acid), primary alcohols (hexacosanol, octacosanol, triacontanol), hydrocarbons $\left(\mathrm{C}_{17-33}\right.$, nonacosane, hentriacontane), secondary alcohols (nonacosan-10-ol), and B-diketones (hentriacontane-14,16-dione, tritriacontane-16,18-dione) (Baker 1982). Intracuticular waxes, those thought to be within the lamellate region of the matrix, are predominantly short chain $\left(\mathrm{C}_{12-18}\right)$ fatty acids. This type of short chain component may be entirely absent from the epicuticular region, arguing for differing points of origin for material in both regions (Baker 1982). 
The diversity in the hydrophobic constituents of the cuticular membrane will have definite effects on altering in the length of the potential tortuosity factors (Price 1982) and reflection coefficients used in the calculation of xenobiotic cuticular penetration. Species and environmentally caused variability in cuticular composition will make precise and all-encompassing quantitative projections of penetrability very difficult to obtain in the field or under less than completely controlled growth conditions.

\section{Mechanisms and Processes Influencing Foliar Absorption of Organic Residues}

Based on the structural and chemical characteristics of foliar surfaces, the range of chemical characteristics of organic xenobiotics for which there may be concern, and uncertainties associated with the physiological behavior of these compounds (metabolism, translocation), it is clear that we are dealing with a complicated series of chemical and physical processes with respect to mathematical simulation. However, the processes believed to be important and rate limiting with respect to foliar absorption and fate can be defined. Assuming that the mass loading rate to the foliar surface, or dose of a particular organic residue, can be defined or modeled, then several processes controlling foliar absorption can be described. These include foliar persistence/retention, foliar surface reactions affecting residue form and behavior, and absorption from and through the leaf epidermis to the symplast.

Once an organic residue is deposited to a foliar surface, its persistence will affect the extent of its mass transfer from the surface to the leaf interior. The persistence and retention of a particular organic residue will be a function of its volatility and vapor pressure, and the atmospheric conditions surrounding the foliage. It can be assumed that any compound having a vapor pressure in excess of $10^{-6} \mathrm{~mm} \mathrm{Hg}$ is volatile and will be lost back to the air column at some defined rate. This rate will be modified by environmental conditions including temperature, relative humidity, wind speed, and foliar surface wetness. It would be expected that surface wetness will be of nore importance when the hydrophobic or hydrophilic nature of a particular residue is at either extreme. In 
addition, organic residues residing on the foliar surface may be subjected to photodecomposition; this can result in the chemical modification of a range of aromatic compounds, and particularly Polyaromatic Hydrocarbons (PAHs).

The fraction of an organic residue retained on foliar surfaces, and subsequently available for absorption, can be immobilized or chemically modified prior to absorption. Two primary mechanisms can be hypothesized, in addition to photolytic processes. Microflora, associated with plant surfaces, could act as initial sinks for a residue resulting in its fixation or metabolism. However, this mechanism is not generally believed to be of significant magnitude to influence absorption. The second, and possible most important process, would be irreversible chemical binding of the residue to foliar surface constituents. Although data are lacking it can be assumed that polar residues, in particular, could be tightly bound to charged structures comprising the plant cuticle. It is less likely that hydrophobic residues would be significantly retained by this adsorption mechanism.

Several routes of entry exist for the transfer of organic residues from foliar surfaces to the interior symplast. The first would involve entry of volatile forms through the stomate and into the substomatal chamber. However, the fact that the surfaces of the substomatal chamber are suberized would result in the need for further transport to be dependent on mobility along either the aqueous or hydrophobic pathways of entry. Although some could be conducted along thin films of water through the stomata and into the leaf interior, it is assumed that the major transport route will be through the established foliar structures of the leaf; this would indicate that more polar, water soluble residues would be transported via aqueous routes through the cuticle. These could include either specialized absorptive structures such as the hypothetical ectodesmata discussed above, or structural imperfections resulting in apoplastic continuity. The route of entry for the less water soluble organic residues would be through the hydrophobic structures comprising the cuticle. The latter would be highly dependent on the relative solubility of the residue in the waxes and lipids that make up the non-wettable portion of the cuticle. 


\section{CUTICULAR MODELS}

\section{SUITABILITY OF AVAILABLE INTEGRATED MODELS}

The cuticle, although an effective protective covering of plant surfaces, is permeable to both polar and nonpolar material. Traditionally the high content of insoluble cutin, low content of protein, and large cross-sectional diameter would argue for a diffusion mechanism to explain this permeability. Most mathematical treatments of cuticular transport therefore will be based on Fick's First Law:

$$
\begin{aligned}
& J_{j}=-D_{j}\left(d c_{j} / d x\right) \\
& \text { Where: } \begin{aligned}
J_{j}= & \text { Flux of species } j \\
D_{j}= & \text { Diffusion coefficient of species } j \\
d_{j} / d x= & \text { Change in concentration gradient for species } j \text { in the } \\
& \quad x \text { direction (Nobel 1974). }
\end{aligned}
\end{aligned}
$$

The literature search for mathematical treatments conducted for this study produced four primary sources: Davis et al. (1979); Price (1975, 1976, 1978, 1982); Hamilton et al. (1982); and Schönherr (1976, 1978, 1982); Reiderer and Schönher $(1984,1985)$. Their respective descriptions of the more recent treatments of this problem will be considered sequentially.

\section{Model of Davis (Davis et al, 1979)}

Davis and his coworkers assumed that permeability depends primarily, in the ideal case, on the thickness and characteristics of the membrane and the properties of the permeant. In order to relate these properties between species and provide a common base for studies of other herbicides, they calculated permeability coefficients $\left(\mathrm{K}_{\mathrm{p}}\right)$ from data found in the literature using the formula: 


$$
K_{p}=\left([R] V_{R} / \Delta t\right)(1 / A)(1 /[D]) \text { in } \mathrm{cm} \mathrm{s}^{-1}
$$

$$
\text { Where: } \begin{aligned}
{[\mathrm{R}] } & =\text { receiver concentration } \\
\mathrm{V}_{\mathrm{R}} & =\text { receiver volume } \\
\Delta \mathrm{t} & =\text { time interval } \\
\mathrm{A} & =\text { area } \\
{[\mathrm{D}] } & =\text { donor concentration }
\end{aligned}
$$

The calculations they completed were for fluxes over short periods of time and assuming that [D] was constant. While they tried to account for the concentration gradient and membrane area, they did not address other variations in membrane composition. This variation could account for some of the observed differences between expected permeability and molecular weight of the individual compounds. The results of these calculations, given in condensed form in Table 3 are useful, however, and may be compared to other authors who use slightly different terminology (c.f. permeance coefficient of Schönherr below).

\section{Model of Price (Price 1982)}

C.E. Price in studies relating the movement of pesticides into the leaves of plants (Price 1982) also approached the problem as one primarily of diffusion. He therefore modified the initial equation from Nobel (1974) to read:

$$
\begin{aligned}
& \mathrm{J}=\mathrm{P}\left(\mathrm{C}_{\mathrm{o}}-\mathrm{C}_{\mathrm{i}}\right) \text { in units of moles } \mathrm{cm}^{-2} \mathrm{~s}^{-1} \\
& \text { Where: } \mathrm{J}=\text { flux } \\
& \mathrm{C}_{\mathrm{O}}=\text { concentration of solute outside cuticle } \\
& \mathrm{C}_{\mathrm{i}}=\text { concentration of solute inside the cuticle } \\
& \mathrm{P}=\text { permeability coefficient }
\end{aligned}
$$


TABLE 3. Permeability Coefficients $\left(\mathrm{K}_{\mathrm{p}}\right)$ of Cuticles and Membranes from Various Organic Compounds, from Davis et al. (1979)

\begin{tabular}{|c|c|c|c|c|c|}
\hline Substrate & $\begin{array}{l}\text { Mol. } \\
\text { Wt. }\end{array}$ & $\begin{array}{c}\text { Cuticle or Membrane } \\
\text { type } \mathrm{e}^{\mathrm{a}, \mathrm{b}}\end{array}$ & $\mathrm{VR} / \mathrm{VD}^{\mathrm{C}}$ & $\begin{array}{l}{[\mathrm{D}] \propto(\mathrm{M})} \\
1 \times 10^{3 \mathrm{~d}}\end{array}$ & $\begin{array}{l}\mathrm{K}_{\mathrm{p}}\left(\mathrm{cm} \mathrm{s}^{-1}\right. \\
\left.1 \times 10^{4}\right)^{\mathrm{e}}\end{array}$ \\
\hline TCA & 163.5 & Citrus mitis ${ }^{3}$ & 19 & 0.015 & 0.0022 \\
\hline Acetamide & 59 & Eucalyptus gummifera 12 & $\leq 1$ & 2000 & $0.000054^{*}$ \\
\hline Aminotriazole & 84 & Citnus mitis ${ }^{3}$ & 19 & 0.027 & 0.0032 \\
\hline $\begin{array}{l}\text { 2-Chloro-N- } \\
\text { isopropyl-acetamide }\end{array}$ & 135.5 & Apricot ${ }^{2}$ & 2.25 & 0.045 & $0.036^{*}$ \\
\hline Benzyl alcohol & 108 & $\begin{array}{l}\text { Cellulose ester disc } \\
+ \text { lipid }^{4}\end{array}$ & 1 & 1.0 & 0.5 \\
\hline Maleic hydrazide & 112 & $\begin{array}{l}\text { Apple }^{2} \\
\text { Tomato fruit } 13\end{array}$ & $\begin{array}{l}1 \\
10\end{array}$ & $\begin{array}{l}0.22 \\
0.25\end{array}$ & $\begin{array}{l}0.1 \\
0.004\end{array}$ \\
\hline 2,4-D & 221 & $\begin{array}{l}\text { Cellulose ester disc } \\
+ \text { lipid }^{4} \\
\text { Tomato fruit }^{1} \\
\text { Tomato }^{1} \text { fruit }^{8} \\
\text { Orange }^{8} \\
\text { Pyrus communis } 8 \\
\text { Apple }^{8}{ }^{8} \\
\text { Apricot }^{8}\end{array}$ & $\begin{array}{l}1 \\
20 \\
25 \\
25 \\
25 \\
25 \\
25\end{array}$ & $\begin{array}{l}1.0 \\
\\
0.16 \\
0.1 \\
0.1 \\
0.1 \\
0.1 \\
0.1\end{array}$ & $\begin{array}{l}0.2 \\
\\
0.09 \\
0.01 \\
0.002 \\
0.006 \\
0.002 \\
0.003\end{array}$ \\
\hline 2-Chloro-acetanilide & 169.5 & Apricot ${ }^{2}$ & 2.25 & 0.065 & $0.0079 *$ \\
\hline $\begin{array}{l}\text { 1-Naphthyl- } \\
\text { acetic acid }\end{array}$ & 186 & $\begin{array}{l}\text { Tomato fruit } \\
\text { Pear } \\
\text { Pear } \\
\text { Pear } \\
\text { Pear } 6 \\
\text { Pear } \\
\text { Citrus aurantium } 10 \\
\quad \text { pH } 3.0 \\
\quad \text { pH } 4.2\end{array}$ & $\begin{array}{l}25 \\
25 \\
2500 \\
25 \\
25 \\
1 \\
1\end{array}$ & $\begin{array}{l}0.5 \\
0.5 \\
0.05 \\
0.5 \\
0.5 \\
\\
0.15 \\
0.15\end{array}$ & $\begin{array}{l}0.01 \\
0.003 \\
0.3 \\
0.001 \\
0.002 \\
\\
0.0037 \\
0.0015\end{array}$ \\
\hline Diphenamid & 239 & Tomato fruit ${ }^{9}$ & 25 & 0.01 & 0.004 \\
\hline Triarimol & 331 & Apple ${ }^{11}$ & $\geq 2000$ & 0.6 & 0.001 \\
\hline Carbaryl & 201 & Citrus mitus 3 & 19 & 0.002 & 0.0048 \\
\hline Thiabendazole & 201 & 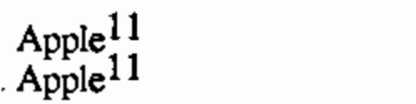 & $\begin{array}{l}1 \\
2000\end{array}$ & $\begin{array}{l}0.25 \\
1.0\end{array}$ & $\begin{array}{l}<0.1 \\
0.0001\end{array}$ \\
\hline
\end{tabular}


TABLE 3 (Contd) from Davis et al. (1979).

\begin{tabular}{|c|c|c|c|c|}
\hline rate & $\begin{array}{l}\text { Mol } \\
\text { Wt. }\end{array}$ & $\begin{array}{l}\text { Cuticle or Membrane } \\
\text { troe a,b }\end{array}$ & $\mathrm{v}_{\mathrm{R}} / \mathrm{N}_{\mathrm{D}}^{\mathrm{c}}$ & $\mathrm{K}_{\mathrm{p}}\left(\mathrm{cm} \mathrm{s}^{-1}\right.$ \\
\hline
\end{tabular}

$\begin{array}{llllll}\text { Simazine } & 201.5 & \text { Apple }^{2} & 1 & 0.029 & 0.4 \\ \text { Dicloran } & 207 & \text { Citrus mitus }^{3} & 19 & 0.017 & 0.010 \\ \text { Benomyl } & 290 & \begin{array}{l}\text { Apple } \\ \text { 11 }\end{array} & \geq 2000 & 0.66 & 0.0005 \\ & & \text { ime }^{11} & \geq 2000 & 0.66 & 0.0005\end{array}$

\footnotetext{
a. All cuticles are astomatous.

b. Superscript indicates article data was taken from. See list of table references.

c. Volume ratio for static receiver and donor compartments respectively.

d. Initial donor concentration.

e. Permeability coefficient, also defined as Permeance $\left(\mathrm{P}_{\mathrm{D}}\right)$ by Schonherr (1978).

* Denotes a published value of $\mathrm{K}_{\mathrm{d}}$. All others were calculated according to Eq. (2)
}

\section{REFERENCES FOR TABLE 3}

1. Bukovac, M. J., J. A. Sargent, R. G. Powell, and G. E. Blackman. 1971. J. Exptl. Bot. 22:598.

2. Darlington, W. A., and N. Cirulis. 1963. Plant Physiol. 38:462.

3. Davis, D. G., J. S. Mullins, G. E. Stolzberg, and G. D. Booth. 1979. Pestic. Sci. 10:19.

4. Kennedy, C. D. 1971. Pestic. Sci. 2:69.

5. Norris, R. F., and M. J. Bukovac. 1969. Physiol. Plant. 22:701.

6. Norris, R. F., and M. J. Bukovac. 1972a. Plant physiol. 49:615.

7. Norris, R. F., and M. J. Bukovac. 1972b. Pestic. Sci. 3:705.

8. Norris, R. F. 1974. Am. J. Bot. 61:74.

9. Robertson, M. M., P. H. Parham, and M. J. Bukovac. 1971. J. Agric. Food Chem. 19:754.

10. Schönherr, J. 1976. Biochem. Physiol. Pflanz. 170:309.

11. Solel, Z., L. V. Edgington. 1973. Phytopathology 63:505.

12. Whitecross, M. I., and F. V. Mercer. 1972. Aust. J. Bot. 20:1.

13. Yamada, Y., S. H. Wittwer, and M. J. Bukovac. 1965. Plant Physiol. 40:170. 
The varied results observed for Eq. (9) requires that $P$ is further defined as:

$$
\mathrm{P}=(\mathrm{D})(\mathrm{K}) /(\mathrm{l})(\Delta \mathrm{x})
$$

$$
\text { Where: } \begin{aligned}
\mathrm{D} & =\text { diffusion coefficient } \\
\mathrm{K} & =\text { partition coefficient } \\
\Delta \mathrm{x} & =\text { thickness of the cuticle } \\
\mathrm{l} & =\text { tortuosity factor }
\end{aligned}
$$

More quantitatively $\mathrm{D}$ is defined by the Stokes-Einstein equation as:

$$
\begin{aligned}
& \mathrm{D}=\left(\mathrm{k}^{\mathrm{B}}\right)(\mathrm{T}) /(6 \pi \mathrm{r})(\eta) \\
& \text { Where: } \begin{aligned}
\mathbf{k}^{\mathrm{B}} & =\text { Boltzmann constant } \\
\mathrm{T} & =\text { absolute temperature } \\
\mathrm{r} & =\text { radius of the solute molecule } \\
\eta & =\text { viscosity of the solvent }
\end{aligned}
\end{aligned}
$$

By substituting the Stokes-Einstein equation in Fick's first law Price (1982) produced:

$$
J=\left[\left(k^{B}\right)(T)(K) /(6 \pi r)(\eta)(\Delta x)(l)\right]\left(C_{0}-C_{i}\right)
$$

This equation provides a means of calculating fiux across the cuticle dependent on a number of factors which may be measured directly, or would have to be inferred from other measurements.

The partition coefficient ( $K$ ) (not the same as the $K_{p}$ of Davis above) is conventionally expressed as the logarithm of the ratio of the solubility in water and octanol and may range from 2.2 for the systemic fungicide ethirimol to 6.5 for the 
nonsystemic insecticide permethrin (Price 1982). These values however, may not reflect actual data obtained from cuticles differing in chemical composition at their inner and outer faces (Schönherr 1978). Further, the $\mathrm{K}$ values for ionizable compounds (e.g., 2,4-D) may also depend on $\mathrm{pH}$ (Reiderer and Schönherr 1984).

Rate of transfer across the cuticle may be further influenced by the viscosity, or resistance to flow, of the cuticular lipids. This viscosity and associated structural integrity will vary with temperature. The crystalline-like epicuticular wax of citris cuticles have been shown to change in properties near $40^{\circ} \mathrm{C}$ (Schönherr 1978), becoming fluid-like and less permeable to herbicides.

The subsequent path the penetrating molecules would be forced to take may be much longer than the cuticular diameter. It has been proposed that the path of a hydrophilic molecule follows that of the carbohydrate strands of the secondary cuticle (c.f. Figure 1) (Price 1982). This added distance has been called by Price (1982) the tortuosity factor (1) which, he states, there are no values known at this time. He also felt that lipophilic molecules would run a parallel path over a similar distance. This would, therefore, indicate that the lipophilic molecules would not have a significant advantage over the hydrophilic compounds.

Finally, in addition to the factors described above, Price proposed the existence of differing partitioning coefficients on either side of the cuticle capable of varying $\mathrm{C}_{\mathrm{O}}$ and $\mathrm{C}_{\mathrm{i}}$. Quantitative estimates of these coefficients would be extremely difficult. Determination of the inner cuticular concentration, $C_{i}$, important in estimating the partitioning coefficients, is also difficult because of the variabilities in the internal conditions which regulate it. These are not known but may be primarily regulated through the maintenance of lower concentrations on the plasmalemma side of the epidermal cell wall. Price felt that this may be accomplished in one of four ways: 
1. Changing the physical properties of the solute upon exiting the cuticle.

2. Washing the solute from the vicinity of penetration via apoplastic water flow.

3. Binding the solute to remove it from the soluble pool.

4. Accumulate the material behind cellular and vacuolar membranes (plasmalemma, and tonoplast).

These mechanisms however, do not directly address the problem of unstired layers within the cuticle, or in close proximity to both its surfaces. These are thought to be very important in accounting for the movement of water in this region (Boyer 1984) and may concomitantly affect solute movement.

Precise determination of the variable components of Eq. (12) would be rather time consuming. They would also change with age and growth conditions. Quantitative estimates would therefore require a standardized system operating under controlled conditions.

\section{Model of Hamilton (Hamilton et al. 1982)}

Hamilton and coworkers have adopted an approach initially used by Price (1974) and have sought to derive quantitative estimates of herbicide uptake (specifically Flamprop-methyl,or methyl ( \pm )-2-(N-(3-chloro-4-flourophenyl)benamido)-propionate) by wheat. A diagrammatic view of their approach is shown in Figure 2. Transmembrane, or transcuticular movement of a substance applied at concentration $c_{1}$ in compartment 1 involves: a) partition across the external/lipid interface; b) diffusion through the lipid membrane; and c) desorption by partition across the lipid/aqueous interface into compartment 3. 


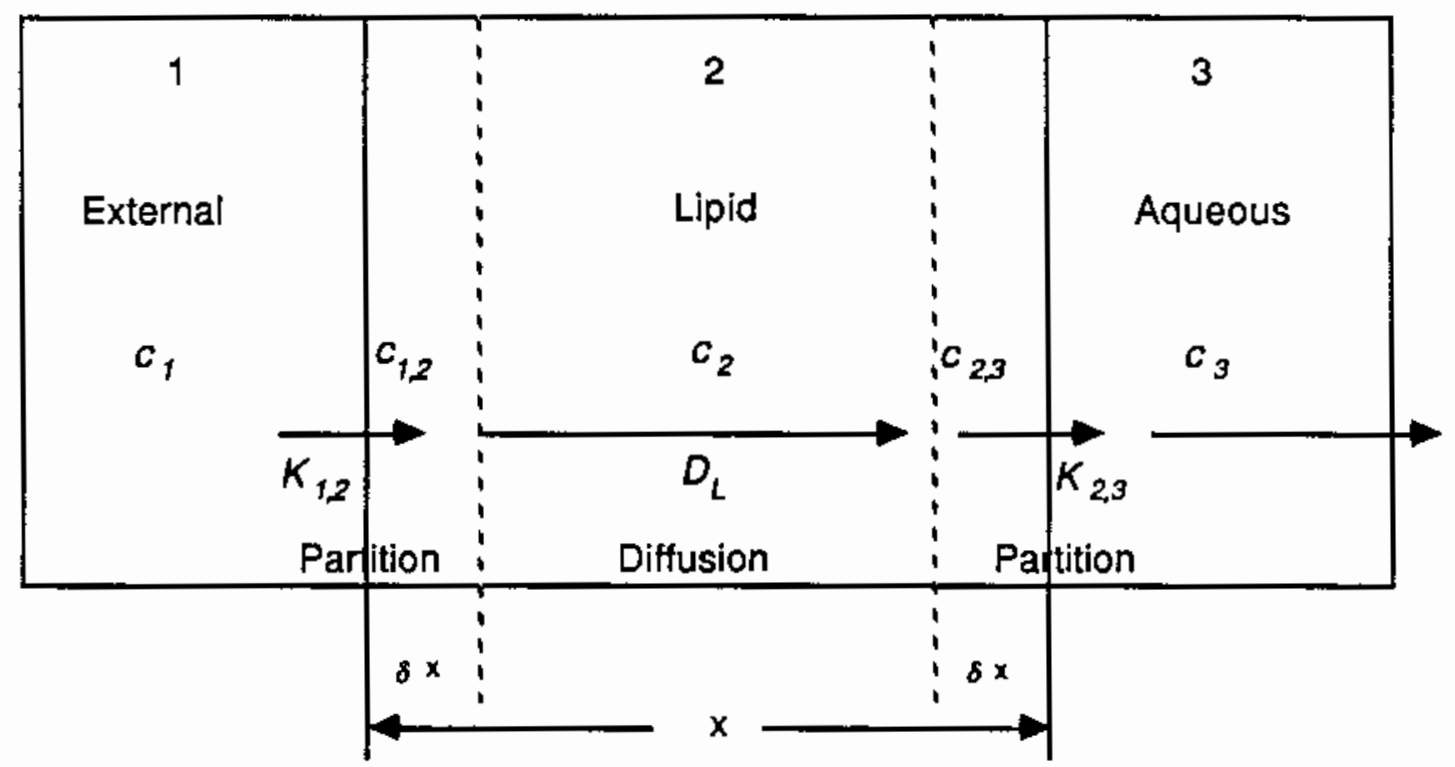

FIGURE 2. Model of Foliar Uptake According to Hamilton et al. (1982) Based on That of Price (1974). The Cuticle is Represented by a Lipid Membrane Separating External and Internal(aqueous) Phases. Movement is by Diffusion.

Within compartment 3 , which may be considered to physically represent the apoplast, further movement can be by diffusion or by movement in flowing liquid streams. In compartment 2, rate of penetration per unit of membrane cross section will be influenced by an additional six parameters:

1. The concentration $\left(c_{1}\right)$ of diffusant on the external side

2. The concentration $\left(c_{3}\right)$ of diffusant in the aqueous phase

3. The diffusion coefficient of the diffusant in the lipid $\left(D_{L}\right)$

4. The thickness of the lipid membrane $(\mathrm{x})$

$5 \&$ 6. The partition coefficients $K_{1,2}$ and $K_{2,3}$ for the transfer of the substance across the interfaces of the membrane. 
Bringing these together, again with a modified Fick's first law, flow through the membrane is expressed as:

$$
\mathrm{j}=\left(\mathrm{D}_{\mathrm{L}}\right)(\Delta \mathrm{c} / \mathrm{x})=\left(\mathrm{D}_{\mathrm{L}}\right)\left[\left(\mathrm{c}_{1,2}-\mathrm{c}_{2,3}\right) / \mathrm{x}\right]
$$

Where: $\quad c_{1,2}$ and $c_{2,3}=$ concentrations of substances at the interfaces external/lipid and lipid/aqueous, respectively.

The values for $c_{1,2}$ and $c_{2,3}$ will be dependent upon $K_{1,2}$ and $K_{2,3}$, respectively. Partition coefficients $(\mathrm{K})$ are defined as the ratio of the concentration of a solute in the material of the membrane to that in equilibrium outside it in the aqueous phase (Nobel, 1974). The partition coefficients as given above (Price, 1982) are conventionally expressed as the logarithm of the ratio of the compound's solubility in water and octanol. However, the partition value for the cuticle may not be the same as octanol and will not be the same in different parts of the cuticle, especially if there is a significant water volume within the cuticle or inherent variations in cuticular lipid composition which are quite common (see above). Hamilton et al.(1982) adapted the conventional application of the expression. They suggested that if, for a hipophilic substance such as the herbicide they were studying, $\mathrm{K}_{2,3}$ was high and $\mathrm{c}_{3}$ small, a build-up of diffusant at the lipid/aqueous interface of the cuticle to that of near outside levels would occur. The concentration difference $(\Delta c)$ across the lipid membrane of the cuticle itself would, therefore, be small and the further uptake of the substance would be inhibited.

Their initial study (Hamilton et al. 1982) indicated that such may be the case and that foliar uptake of flamprop-methyl could be broadly interpreted in quantitative terms by this simple compartment model. However, there were large variations observed in the data which the authors attributed to changes in diffusion through the epicuticular wax. The variability of this structure, discussed above, indicates that these calculations inay be appropriate for approximations of flux but more accurate estimations would require a more standardized quantitative approach. 
Models of Schönherr and Reiderer (Schönherr 1976-82; Reiderer and Schönherr $\underline{1984-86)}$

Schönherr and his coworkers refer to isolated cuticles in their natural state as the cuticular membrane (CM). By exhaustive extraction with a mixture of $1: 1(\mathrm{v} / \mathrm{v})$ chloroform:methanol they produce a soluble cuticular lipid fraction (SCL) and an insoluble polymer matrix (PM) (Schönherr 1978). They utilized only astomatous cuticles for their transport measurements. These were placed in a septum between two solution chambers which also contained motorized stirrers to reduce or eliminate the effects of unstirred layers (Kerler et al. 1984). In addition, they attempted to approximate a steady-state condition during all measurements.

In their latest experiments (Reiderer and Schönherr 1985) the following formulae were used in their calculations:

$$
\mathrm{J}=\left[(\mathrm{D})(\mathrm{A}) / /\left(C_{1}-C_{2}\right) \text { in } \mathrm{mol} \mathrm{s}^{-1}\right.
$$

$$
\begin{aligned}
& \text { Where: D }=\text { diffusion coefficient }\left(\mathrm{m}^{2} \mathrm{~s}^{-1}\right) \\
& \text { A } \quad=\text { septum area exposed }\left(\mathrm{m}^{2}\right) \\
& 1 \text { = thickness of membrane }(\mathrm{m}) \\
& C_{1} \text { and } C_{2}=\text { concentrations of the penetrant at the two } \\
& \text { faces of the septum }\left(\mathrm{mol} \mathrm{m}^{-3}\right) \text { respectively. }
\end{aligned}
$$

If $C_{1}$ is higher than $C_{2}$ a net flux will occur from side 1 to 2 (Crank and Park 1968).

In most cases only the bulk solution concentrations are known. This means the internal concentrations must be obtained by: 


$$
C_{1}=\mathrm{K}_{1} C_{1}
$$

and

$$
\begin{aligned}
& C_{2}=\mathrm{K}_{2} C_{2} \\
& \text { Where: } \quad \mathrm{K}=\text { Partition coefficient } \\
& C=\text { concentration in the solution. }
\end{aligned}
$$

For a homogeneous membrane with the same solvent on both sides $K_{1}=K_{2}=K$ and:

$$
\mathrm{p}=(\mathrm{D})(\mathrm{K})
$$

Where: $p=$ permeability coefficient.

The permeability coefficient is independent of membrane thickness and membrane and penetrant specific.

Substituting for internal and external concentrations Eq. (14) becomes:

$$
\mathrm{J}=[(\mathrm{p})(\mathrm{A}) /]]\left(C_{1}-C_{2}\right)
$$

This permeability coefficient is again specific for the membrane material and penetrant (Reiderer and Schönherr 1985).

Differing from the formula of Price (Eq. 12), Reiderer and Schönherr (1985) employed a proportionality factor to relate the flow across a biological membrane. This factor, a permeance coefficient ( $\mathrm{P}$ in $\mathrm{m} \mathrm{s}^{-1}$ ), along with the extrapolated holdup time given below in Eq. (20), takes over part of the function of Price's (1982) tortuosity factor (see above), permitting an attempted estimate of the penetration (not possible with the 
tortuosity factor). This permeance coefficient is essentially the same as the permeability coefficient $\left(\mathrm{K}_{\mathrm{p}}\right)$ of Davis et al. (1979) and is defined as:

$$
\mathrm{P}=\mathrm{p} / \mathrm{l}
$$

This changes Eq. (17) to form:

$$
\mathrm{J}=(\mathrm{P})(\mathrm{A})\left(C_{1}-C_{2}\right)
$$

Reiderer and Schönherr (1985) utilized these equations and previously developed instrumentation (Kerler et al. 1984) to study the penetration of (2,4-Dichlorophenoxy) acetic acid (2,4-D) through plant cuticles. A detailed description of this work will be conducted here since it is one of the most complete and quantitative found during the literature search for this paper.

Their initial approach was to determine 2,4-D permeance coefficients for the cuticular membranes and polymer matrix membranes from leaves or fruits of the 11 species chosen, which included cuticles from fruits (Lycopersicon, Capsicum and Solanum) and leaves (Citrus, Clivia, Ficus, Hedera, Nerium, Olea, and Pyrus Conf and Will). These are given in Table 4.

The diffusion coefficients (D) for 2,4-D in the membranes were calculated from the extrapolated holdup times $\left(\mathrm{t}_{\mathrm{e}}\right)$ and membrane thickness (Crank and Park 1968).

$$
t_{e}=l^{2} / 6 D
$$

Where: $t_{e}=$ Extrapolated holdup times for each of the species used calculated by solving the linear regression equation for time of plots of amount of diffused 2,4-D vs time if the amount diffused $=0$. 
TABLE 4. 2,4-D Permeance Coefficients of Plant Cuticular Membranes P(CM) and Polymer Matrix Membranes P(MX). According to Reiderer and Schönherr (1985).

\begin{tabular}{|c|c|c|c|}
\hline Species & $\begin{array}{c}\mathrm{P}(\mathrm{CM})^{\mathrm{a}} \\
\left(\mathrm{x} 10^{-11} \mathrm{~m} \mathrm{~s}^{-1}\right)\end{array}$ & $\begin{array}{l}\mathrm{P}(\mathrm{MX})^{\mathrm{a}} \\
\left(\mathrm{x} 10^{-7} \mathrm{~m} \mathrm{~s}^{-1}\right)\end{array}$ & $\mathrm{P}(\mathrm{MX}) / \mathrm{P}(\mathrm{CM})$ \\
\hline Capsicum & $2723(646-4800)$ & $12.4(11.1-13.6)$ & 46 \\
\hline Lycopersicon & $2555(1607-3503)$ & $7.3(5.8-8.8)$ & 29 \\
\hline Solanum & $336(150-522)$ & $52.3(44.4-60.2)$ & 1557 \\
\hline Citrus & $28(17-40)$ & $5.0(2.5-7.4)$ & 1767 \\
\hline Clivia & $13(10-16)$ & $5.0(2.5-7.4)$ & 3876 \\
\hline Ficus & $10(7-13)$ & $9.1(8.1-10.1)$ & 9192 \\
\hline Hedera & $46(30-63)$ & $23.3(16.1-30.3)$ & 5043 \\
\hline Nerium & $18(17-20)$ & $1.2(0.7-1.7)$ & 656 \\
\hline Olea & $267(90-444)$ & $65.2(58.3-71.7)$ & 2442 \\
\hline Pyrus Conf & $189(103-275)$ & $63.0(52.3-73.6)$ & 3333 \\
\hline Pyrus Will & $133(36-230)$ & $29.0(27.1-31.2)$ & 2181 \\
\hline
\end{tabular}

a. Values of $\mathrm{P}$ for $\mathrm{CM}$ and $\mathrm{MX}$ are means of 6 to 13 membranes each. Lower and upper limits of the $95 \%$ confidence intervals are given in parenthesis.

For membranes having a common $\mathrm{D}$, a plot of $\mathrm{t}_{\mathrm{e}} \mathrm{vs} \mathrm{l}^{2}$ should give a straight line whose slope would be $(6 \mathrm{D})^{-1}$. In their study Riederer and Schönherr observed a significant correlation in $\mathrm{D}$ for the $\mathrm{CM}$ of fruits or leaves respectively. The large differences in cuticle thickness is thought to be responsible for the large variabilities in $t_{e}$ shown in Table 5. 
TABLE 5. Gravimetric Thickness of the Cuticles (1) used to Extrapolate Holdup Times for the Diffusion of 2,4-D Across Cuticular Membranes $\left[\mathrm{t}_{\mathrm{e}}(\mathrm{CM})\right]$ and Polymer Matrix Membrane $\left[t_{e}(M X)\right]$ (from Reiderer and Schönherr 1985).

\begin{tabular}{|c|c|c|c|c|}
\hline Species & $\begin{array}{c}1^{\mathrm{a}} \\
\left(10^{-6} \mathrm{~m}\right)\end{array}$ & $\begin{array}{c}\mathrm{t}_{\mathrm{e}}(\mathrm{CM})^{\mathrm{a}} \\
\left(10^{3} \mathrm{~s}\right)\end{array}$ & $\begin{array}{c}t_{e}(M X)^{a} \\
(s)\end{array}$ & $t_{e}(\mathrm{CM}) / \mathrm{r}_{\mathrm{e}}(\mathrm{MX})$ \\
\hline Capsicum & $9.2(6.1-12.3)$ & $2.71(1.52-3.9)$ & $851(552-1149)$ & 3.2 \\
\hline Lycopersicon & $8.1(7.4-8.7)$ & $1.80(1.52-2.09)$ & $1215(858-1572)$ & 1.5 \\
\hline Solanum & $6.3(5.3-7.3)$ & $0.83(0.58-1.08)$ & $42(36-48)$ & 19.8 \\
\hline Cirnus & $2.6(2.5-2.7)$ & $20.88(16.68-25.09)$ & $393(247-539)$ & 53.1 \\
\hline Clivia & $8.9(8.3-9.5)$ & $59.6(51.49-67.23)$ & $333(207-459)$ & 178.3 \\
\hline Ficus & $9.8(9.1-10.5)$ & $70.29(63.12-77.46)$ & $219(178-260)$ & 320.9 \\
\hline Hedera & $4.6(4.3-4.9)$ & $18.32(13.36-23.27)$ & $53(45-60)$ & 345.7 \\
\hline Nerium & $10.7(8.8-12.6)$ & $132.21(102.98-161.44)$ & $2260(2180-2340)$ & 58.5 \\
\hline Olea & $6.2(5.4-7.0)$ & $24.40(15.11-33.69)$ & $79(56-102)$ & 308.9 \\
\hline Pyrus Conf & $3.5(3.2-3.8)$ & $2.09(1.13-3.06)$ & $29(14-45)$ & 41.7 \\
\hline Pyrus Will & $3.6(3.3-3.9)$ & $2.47(0.56-4.39)$ & $74(67-82)$ & 33.4 \\
\hline
\end{tabular}

a. Values are means of 6 to 13 membranes. Lower and upper limits of $95 \%$ confidence intervals are given in parenthesis

If, as mentioned above $t_{e}$ is plotted against gravimetrically determined $\mathrm{l}^{2}$ a mean diffusion coefficient $\left(D^{*}\right)$ can be calculated from all of the slopes. Values calculated in this manner for 2,4-D are given in Table 6. The extraction of the SCL produced a marked increase in the $\mathrm{D}^{*}$ for the $\mathrm{MX}$ alone, however this was less than what was reported by other authors with the removal of this material (Price 1982; Whitehouse et al. 1982).

Under conditions of constant D, it follows from Eq. (20) that differences in permeability coefficients between species must be due to different partition coefficients (K). This is true if the membrane is homogeneous, the sorption isotherm for the 
TABLE 6. Mean Diffusion Coefficients (D*) for 2,4-D in Plant Cuticular Membranes (CM) and Polymer Matrix Membranes (MX). Adapted from Reiderer and Schönherr (1985).

Type of material

$D^{*}\left(\mathrm{~m} \mathrm{~s}^{-1}\right)^{a}$

\begin{tabular}{cc} 
CM & \\
Fruits & \\
Leaves & $1.01 \times 10^{-15}\left(3.07 \times 10^{-15}\left(1.25 \times 10^{-16}-2.72 \times 10^{-16} \times 10^{-16}\right)\right.$ \\
MX all species & $1.32 \times 10^{-14}\left(0.73 \times 10^{-14}-7.07 \times 10^{-14}\right)$ \\
\hline
\end{tabular}

a. Values were calculated from plots of the extrapolated holdup times versus. the square of gravimetric thicknesses. Lower and upper limits of $95 \%$ confidence intervals are given in parenthesis.

penetrant is linear, and D is independent of concentration (Crank and Park 1968). Estimates of $\mathrm{K}$ may come from direct sorption experiments, or may be calculated as shown in Table 7.

Employing this evidence, Reiderer and Schönher (1985) concluded that equation (16) would hold only if: a) the membrane is homogeneous; b) the sorption isotherm for the penetrant in the membrane is linear, and c) D is independent of concentration. Their experimentally obtained mean diffusion coefficients as calculated above may be regarded as a valid overall estimate under their experimental conditions. Their partiotion coefficients which were effective in the transmembrane diffusion of 2,4-D were estimated from $\mathrm{K}^{\text {calc-trans }}(\mathrm{CM})=0.74 \mathrm{~K}_{\mathrm{dir}}(\mathrm{CM})-13.99$ which was obtained from a plot of directly determined partition coefficients vs. transport partition coefficients for the CM of all of the species studied (Reiderer and Schönhern 1985 Fig.4). These then modified equation (16) to produce:

$$
\mathrm{p}=\mathrm{D}^{*}\left(0.074 \mathrm{~K}_{\mathrm{dir}}-13.99\right)
$$


TABLE 7. Comparison of Determined and Calculated Permeability Coefficients for the Diffusion of 2,4-D Across Plant Cuticular Membranes. Adapted from Reiderer and Schönherr (1985).

\begin{tabular}{|c|c|c|c|c|}
\hline Species & $\mathrm{K}_{\mathrm{dir}}{ }^{\mathrm{a}}$ & $\begin{array}{r}\text { b } \\
\text { K }^{\text {calc-trans, }} \\
\left(10^{15} \mathrm{~m}^{2} \mathrm{~s}^{-1}\right)\end{array}$ & $\begin{array}{c}\mathrm{p}^{\mathrm{calc}}, \\
\left(10^{15} \mathrm{~m}^{2} \mathrm{~s}^{-1}\right)\end{array}$ & $\begin{array}{l}\mathrm{p}^{\mathrm{det},}, \\
\left(\times 10^{15} \mathrm{~m}^{2} \mathrm{~s}^{-1}\right)\end{array}$ \\
\hline Capsicum & 579 & $29.1(12.3-45.9)$ & $116.7(37.8-265.8)$ & $281(65.5-496)$ \\
\hline Lycopersicon & 428 & $17.8(9.6-26.0)$ & $71.4(29.5-150.5)$ & $205(126-283)$ \\
\hline Solaniem & 424 & $17.5(9.4-25.8)$ & $70.2(28.9-149.4)$ & $22.1(7.6-36.6)$ \\
\hline Citrus & 300 & $8.3(0.8-15.6)$ & $1.4(0.1-4.2)$ & $0.7(0.4-1.1)$ \\
\hline Clivia & 240 & $3.9(0-15.6)$ & $0.7(0.1-3.8)$ & $1.1(0.8-1.4)$ \\
\hline Ficus & 315 & $9.4(2.4-16.4)$ & $1.6(0.3-4.5)$ & $1.0(0.7-1.3)$ \\
\hline Hedera & 364 & $13.1(6.5-19.6)$ & $2.2(0.8-5.3)$ & $2.2(1.4-3.0)$ \\
\hline Nerium & 300 & $8.3(0.8-15.8)$ & $1.4(0.1-4.3)$ & $2.0(0.8-3.3)$ \\
\hline Pyrus Conf & 278 & $6.7(0-15.1)$ & $1.1(0.1-4.1)$ & $6.7(3.6-9.8)$ \\
\hline Pyrus Will & 312 & $9.2(2.1-16.3)$ & $1.6(0.3-4.4)$ & $4.9(1.2-8.5)$ \\
\hline
\end{tabular}

Values are means or estimates from linear regression equations; lower and upper limits of $95 \%$ confidence intervals are in parentheses.

a. Partition coefficients determined directly by sorption experiment. Values are taken from Reiderer and Schonherr (1984).

b. Partition coefficients effective in transmembrane diffusion of 2,4-D were estimated from $\mathrm{K}^{\text {calc-trans }}(\mathrm{CM})=0.74 \mathrm{~K}_{\mathrm{dir}}(\mathrm{CM})-13.99$ (obtained from Reiderer and Schönher $1985 \mathrm{Fig} .4$ )

c. Permeability coefficient calculaled according to $\mathrm{p}^{\text {calc }}=\mathrm{D}^{\star} \mathrm{K}^{\text {calc-trans }}$; values for $\mathrm{D}^{\star}$ are taken from Table 6.

d. Permeability coefficient calculated from directy determined permeance (P) and gravimetric thickness (l) according to $\mathrm{p}^{\text {det }}=\mathrm{Pl}$.

This estimate is in actuality not able to provide accurate calculations of the transport properties of plant cuticles within more than a order of magnitude. This is however, we feel, the most quantitative approach for the description of cuticular transport available to date in the open literature. It provides a means of estimating and quantitating the process using parameters which can easily be determined within the laboratory. 


\section{STOMATAL OR GASEOUS DIFFUSION MODELS}

Stomatal models of gaseous diffusion generally fall into two classes: 1) models which focus on the resistance catena concept of Gaastra (1959) using Fick's law; and 2) models which focus on abiotic and biotic factors which influence stomatal resistance or conductance (resistance is the reciprocal of conductance). Models of the first class attempt to locate discrete resistance elements in the catena, predict gaseous concentrations at various points from the outside to the inside of the leaf, and then estimate flux rates between the resistance elements. Models of the second class attempt to parameterize the relationship between the resistance elements and factors which influence them. These models generally lead to the prediction of gaseous concentrations and flux rates at various points in the catena in real time as a function of abiotic or biotic variables.

Models which focus on the resistance catena predict the flux of gases into the leaf. Gas concentrations and resistances are estimated by measuring stomatal geometries or measuring a gross leaf conductance by gas exchange techniques. Resistances are generally broken into aerodynamic, boundary layer, stomatal, cuticular, and mesophyll components (Figure 3). The model of Bennett et al. (1973) used the resistance approach to predict gaseous xenobiotic concentrations in the mesophyll given a concentration outside the leaf. They present data for the diffusion of ozone. O'Dell et al. (1977) developed a resistance model based on stomatal geometry which was able to accurately predict $\mathrm{SO}_{2}$ flux rates. An in-depth review of diffusion resistance models for $\mathrm{H}_{2} \mathrm{O}$ and $\mathrm{CO}_{2}$ based on stomatal geometry is provided by Cooke and Rand (1980). Unsworth et al. (1976) provide a review of resistance based models of gaseous xenobiotic uptake for single leaves. A subsequent review by Unsworth (1981) considers resistance models extended to full canopies. Leuning et al. (1979) developed a resistance model for ozone flux to tobacco under field conditions which considered full canopies. They also compared flux estimates based on gas exchange techniques with those obtained with the Bowen ratio micrometeorological technique. The conclusion was that gas exchange is 


\section{STOMATAL OR GASEOUS DIFFUSION MODELS}

Stomatal models of gaseous diffusion generally fall into two classes: 1) models which focus on the resistance catena concept of Gaastra (1959) using Fick's law; and 2) models which focus on abiotic and biotic factors which influence stomatal resistance or conductance (resistance is the reciprocal of conductance). Models of the first class attempt to locate discrete resistance elements in the catena, predict gaseous concentrations at various points from the outside to the inside of the leaf, and then estimate flux rates between the resistance elements. Models of the second class attempt to parameterize the relationship between the resistance elements and factors which influence them. These models generally lead to the prediction of gaseous concentrations and flux rates at various points in the catena in real time as a function of abiotic or biotic variables.

Models which focus on the resistance catena predict the flux of gases into the leaf. Gas concentrations and resistances are estimated by measuring stomatal geometries or measuring a gross leaf conductance by gas exchange techniques. Resistances are generally broken into aerodynamic, boundary layer, stomatal, cuticular, and mesophyll components (Figure 3). The model of Bennett et al. (1973) used the resistance approach to predict gaseous xenobiotic concentrations in the mesophyll given a concentration outside the leaf. They present data for the diffusion of ozone. O'Dell et al. (1977) developed a resistance model based on stomatal geometry which was able to accurately predict $\mathrm{SO}_{2}$ flux rates. An in-depth review of diffusion resistance models for $\mathrm{H}_{2} \mathrm{O}$ and $\mathrm{CO}_{2}$ based on stomatal geometry is provided by Cooke and Rand (1980). Unsworth et al. (1976) provide a review of resistance based models of gaseous xenobiotic uptake for single leaves. A subsequent review by Unsworth (1981) considers resistance models extended to full canopies. Leuning et al. (1979) developed a resistance model for ozone flux to tobacco under field conditions which considered full canopies. They also compared flux estimates based on gas exchange techniques with those obtained with the Bowen ratio micrometeorological technique. The conclusion was that gas exchange is 




FIGURE 3. Schematic Cross Section of a Dicotyledonous Leaf Showing Pollutant Gas Concentrations and Resistances (from O'Dell et al. 1977).

the preferable method because it is possible to separate plant from soil processes, while this separation is not possible with the Bowen ratio technique.

Models which focus on the abiotic and biotic factors which influence the various resistances are numerous. Most of these focus on stomatal resistance and usually consider only one influencing factor. Multivariate models of stomatal resistance are fewer. Recent models of this type are reviewed later in this document. The model of Avissar et al. (1985) describes the response of stomatal conductance to abiotic factors while that of Kuppers and Schulze (1985) couples the responses of $\mathrm{CO}_{2}$ assimilation and stomatal 
conductance to abiotic factors. Few models of this type have been written for air pollution studies. A comprehensive simulation model of the influence of geothermally related gaseous air pollutants was developed by Kercher (1977). Its final predictions were for biomass production and included submodels of stomatal conductance as influenced by the environment. The model was not validated. Subsequent validation of the model was not found in the literature. The most recent comprehensive model of xenobiotic plant interactions was developed by Hicks et al. (1985). A review of its stomatal submodel is presented below.

The model of O'Dell et al. (1977) for stomatal gaseous uptake is general and demonstrates the major controlling factors and their interrelationships in predicting pollutant uptake. Their model uses a mass transfer approach for gaseous pollutant uptake by leaves in which a series of resistances is summed across a concentration difference. It calculates the aerodynamic and stomatal resistances to uptake, and, in addition, provides qualitative estimates for mesophyll resistance. We will consider only the portion of their model addressing aerodynamic and stomatal resistances. The model of O'Dell et al. (1977) is an improvement over the earlier model of Bennet et al. (1973). O'Dell et al. (1977) shows that the assumption of inverse proportionality with the diffusion coefficient for calculating aerodynamic resistances is invalid.

\section{RESISTANCE MODELS}

\section{Model of O'Dell (O'Dell et al. 1977)}

O'Dell et al. (1977) consider aerodynamic resistance $\left(\mathrm{r}_{\mathrm{a}}\right)$ to be analogous to the resistance to heat or mass transfer in a boundary layer near a flat plate (after Pohlhausen 1921). The equation for laminar flow across a flat plate is as follows:

$$
\mathrm{dk} / \mathrm{D}=\mathrm{d} / \mathrm{Dr}_{\mathrm{a}}=0.664(\mathrm{Re})^{1 / 2}(\mathrm{Sc})^{1 / 3},
$$


where $d$ is the characteristic length of the leaf $(m), k$ is the mass transfer coefficient $(\mathrm{m} / \mathrm{s}), \mathrm{D}$ is the air-gas diffusivity $\left(\mathrm{m}^{2} / \mathrm{s}\right), \mathrm{r}_{\mathrm{a}}$ is the aerodynamic resistance $(\mathrm{s} / \mathrm{m}), \mathrm{Re}$ is the Reynolds number (dimensionless), and $\mathrm{Sc}$ is the Schmidt number (dimensionless). The model considers the total of both sides of the leaf as the area of transport and uses the mean length in the direction of flow as proposed by Parkhurst et al. (1968) to represent the length from the leading edge of the boundary layer. It is cautioned that the exact form of the relationship for $\mathrm{r}_{\mathrm{a}}$ will differ slightly from that in Eq. 22 because leaves differ slightly from a flat plate (Parkhurst et al. 1968). This relationship accounts properly for the variation in diffusivities of pollutants (O'Dell et al. 1977). At wind speeds above 1 $\mathrm{m} / \mathrm{s}$ the aerodynamic resistance becomes small relative to stomatal resistance as found by Hill (1971) and Meidner and Spanner (1959).

O'Dell et al. (1977) models stomatal resistance on the basis of stomatal geometry. They consider the stomatal pore to be a narrow tube opening into an absorptive chamber as in Brown and Escombe (1900), with the effective length of the tube being the length of the stomatal pore plus a length corresponding to that of the substomatal cavity. They use the flux equation of Bird et al. (1960) as follows:

$$
\mathrm{n}_{\mathrm{Al}}=\mathrm{z} 1=\mathrm{pD}\left(\mathrm{w}_{\mathrm{A} 1}{ }^{-\mathrm{w}_{\mathrm{A}}}\right) /\left(\mathrm{z}_{2}-\mathrm{z}_{1}\right)\left(\mathrm{w}_{\mathrm{B}}\right) \ln ,
$$

Where: $\quad n_{A}=$ the flux of pollutant (A) with respect to stationary coordinates $\left(\mu \mathrm{g} \mathrm{m}^{-2} \mathrm{~s}^{-1}\right)$,

$$
\begin{aligned}
& \mathrm{z}_{2,1}=\text { rectangular coordinates }(\mathrm{m}), \\
& \mathrm{p}=\text { the density of air near the leaf }\left(\mu \mathrm{g} \mathrm{m}^{-3}\right),
\end{aligned}
$$$$
\mathrm{D}=\text { the air-gas diffusivity }\left(\mathrm{m}^{2} \mathrm{~s}^{-1}\right) \text {, and }
$$$$
\mathrm{w}_{\mathrm{Ai}}=\text { the mass fraction of pollutant species } \mathrm{A} \text { at point } \mathrm{i}
$$ 
For low concentration pollutant transport, $\mathrm{w}_{\mathrm{A} 1}$ and $\mathrm{w}_{\mathrm{A} 2}$ are small, so $\left(\mathrm{W}_{\mathrm{B}}\right) \ln [$ the logarithmic mean of terminal values of A, see Bird et al. (1960) page 525 for further details] is approximately equal to 1 and Eq. 23 simplifies to:

$$
F_{s}=D\left(C_{o}-C_{\text {int }}\right) / L_{e}
$$

$$
\begin{aligned}
& \text { Where: } \quad \begin{array}{l}
\mathrm{F}_{\mathrm{S}}= \\
\mathrm{n}_{\mathrm{A}} \text { and is the flux into a single pore based on the } \\
\text { cross-sectional area of the stomatal slit. }
\end{array} \\
& \qquad \begin{array}{l}
\mathrm{L}_{\mathrm{e}}=\text { is effective length of the tube, } \mathrm{z}_{2}-\mathrm{z}_{1} \text {, and, } \\
\mathrm{D}=\text { the gas diffusivity. }
\end{array}
\end{aligned}
$$

The diffusive resistance of a single pore, $\mathrm{r}_{\mathrm{p}}$, is then equal to:

$$
r_{p}=L_{e} / D
$$

The resistances of all the pores are then summed in parallel over the leaf to give an estinate of $r_{s}$ as:

$$
r_{s}=4 r_{p} / \pi a b N=4 L_{e} / D \pi a b N,
$$

$$
\text { Where: } \quad \begin{aligned}
& \mathrm{a}=\text { the major length of the opening, } \\
& \mathrm{b}=\text { the minor length of the opening, and } \\
& \mathrm{N}=\text { the number of pores per unit leaf area. }
\end{aligned}
$$

Brown and Escombe (1900) estimated the length for the substomatal cavity to be $\pi(\mathrm{ab})^{1 / 2} / 8$ and therefore, 


$$
\mathrm{L}_{\mathrm{e}}=\mathrm{L}_{\mathrm{s}}+\pi(\mathrm{ab})^{1 / 2} / 8
$$

For a particular leaf, $\mathrm{N}, \mathrm{L}_{\mathrm{e}}$ and a are constant, therefore $\mathrm{r}_{\mathrm{S}}$ is inversely proportional to $b$ and $D$. Thus

$$
r_{s}=q / b D
$$

and

$$
\mathrm{q}=4 \mathrm{~L}_{\mathrm{e}} / \pi \mathrm{aN}
$$

where $\mathrm{q}$ is a stomatal constant. Therefore, if the stomatal resistance can be found at one aperture size, $\mathrm{q}$ can be calculated and $\mathrm{r}_{\mathrm{s}}$ estimated for any aperture and pollutant gas. O'Dell et al. (1977) compared the predictive power of this model with the data of Kuiper (1961) and found it to be highly accurate (Figure 4).

Given that $\mathrm{r}_{\mathrm{s}}$ can be estimated as above it is convenient to estimate pollutant flux and concentration at the mesophyll cell wall with knowledge of ambient concentrations as follows:

$$
\mathrm{F}=\left(\mathrm{C}_{\mathrm{a}}-\mathrm{C}_{\mathrm{o}}\right) / \mathrm{r}_{\mathrm{a}}
$$

and

$$
\mathrm{F}=\left(\mathrm{C}_{\mathrm{o}}-\mathrm{C}_{\mathrm{int}}\right) / \mathrm{r}_{\mathrm{S}}
$$

Where: $\quad \mathrm{F}=$ the flux to the total leaf area $\left(\mu \mathrm{g} \mathrm{m}^{-2} \mathrm{~s}^{-1}\right)$,

$\mathrm{C}_{\mathrm{a}}=$ the atmospheric gas concentration $\left(\mu \mathrm{g} \mathrm{m}^{-3}\right)$, and

$\mathrm{C}_{\text {int }}=$ the gas concentration at the mesophyll cell wall. 


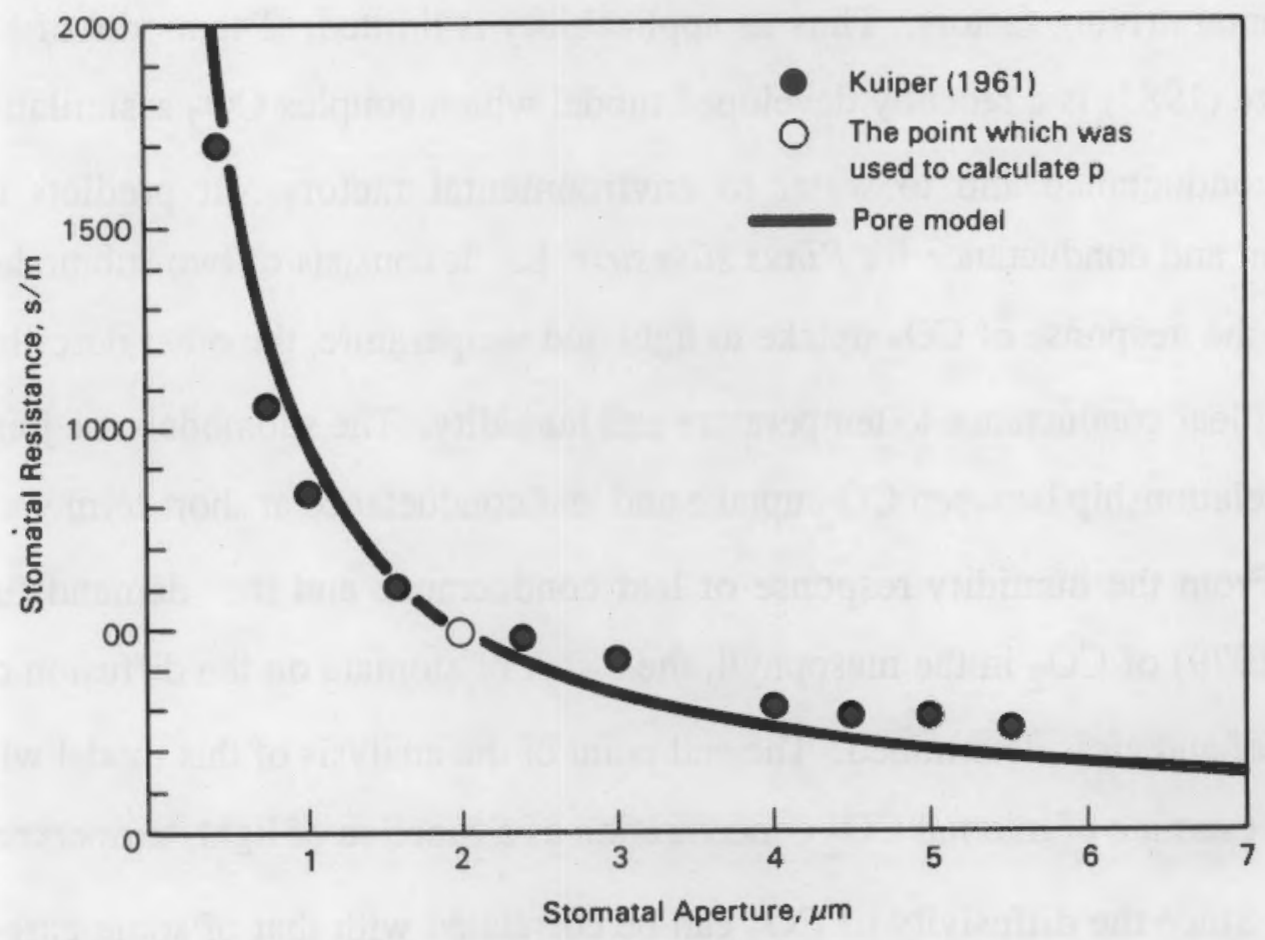

FIGURE 4. Stomatal Resistance as a Function of Stomatal Aperture (Adapted from O'Dell et al. 1977).

By algebra, $C_{O}$ can be eliminated from these two equations yielding:

$$
\mathrm{F}=\left(\mathrm{C}_{\mathrm{a}}-\mathrm{C}_{\text {int }}\right) /\left(\mathrm{r}_{\mathrm{a}}+\mathrm{r}_{\mathrm{s}}\right)
$$

and solving for $\mathrm{C}_{\text {int }}$ yields

$$
C_{\text {int }}=C_{a}-F\left(r_{a}+r_{s}\right) \text {. }
$$

\section{ENVIRONMENTALLY DRIVEN MODELS}

Model of Kuppers and Schulze (1985)

The model of O'Dell et al. (1977) is useful for tying the diffusion of various xenobiotics to stomatal resistance, but does not relate stomatal resistance or stomatal aperture to 
environmental driving factors. Thus its applicability is limited. The model of Kuppers and Schulze (1985) is a recently developed model which couples $\mathrm{CO}_{2}$ assimilation and stomatal conductance and to water to environmental factors. It predicts diurnal assimilation and conductance for Pinus silvestris L. It consists of two submodels, one describing the response of $\mathrm{CO}_{2}$ uptake to light and temperature, the other describing the response of leaf conductance to temperature and humidity. The submodels are joined via the linear relationship between $\mathrm{CO}_{2}$ uptake and leaf conductance at short-term variations of light. From the humidity response of leaf conductance and the demand function (Raschke 1979) of $\mathrm{CO}_{2}$ in the mesophyll, the effect of stomata on the diffusion of $\mathrm{CO}_{2}$ between leaf and air is determined. The end point of the analysis of this model will be to provide an estimate of internal $\mathrm{CO}_{2}$ concentration as a function of light, temperature, and humidity. Since the diffusivity of $\mathrm{CO}_{2}$ can be correlated with that of some gaseous air pollutants, this model should also provide predictions of air pollutant internal concentrations. $\mathrm{CO}_{2}$ assimilation was related to light and temperature as follows:

$$
\begin{aligned}
& A_{(I, T)=A_{\max (T)}[}\left[1-e^{\left.-a_{1}\left(I-I_{c}(T)\right)\right]}\right. \\
& \text { Where; } \begin{aligned}
A_{(I, T)} & =\text { the light response of } \mathrm{CO}_{2} \text { assimilation, } \\
T & =\text { a given leaf temperature }(T), \\
I & =\text { light, and } \\
I_{c(T)} & =\text { the light compensation point at } T .
\end{aligned}
\end{aligned}
$$

The parameter, $a_{1}$, determines the curvature of the light relationship and was found to be independent of temperature.

The light-saturated response of $\mathrm{CO}_{2}$ assimilation to temperature $\left(\mathrm{A}_{\max }(\mathrm{T})\right.$ was described with the following polynomial regression: 


$$
A_{\max (T)}=a_{2} T^{3}+a_{3} T^{2}+a_{4} T+a_{5},
$$

and the temperature dependence of the light compensation point given as:

$$
I_{c(T)}=e^{\left(a_{6} T+a_{7}\right)}
$$

With these three equations $(34,35$, and 36$)$, it is possible describe the response surface of $\mathrm{CO}_{2}$ uptake to light and temperature.

Independent of the above submodel, the temperature response of dark respiration was determined as:

$$
A_{(T, I=0)}=-a_{8} T^{a_{9}}
$$

In the second submodel the response of leaf conductance to temperature and humidity is determined. The response to leaf temperature at a low leaf-air vapor concentration differences $(\Delta w)$ was described as:

$$
g_{\max (T)}=e^{\left(b_{1} T+b_{2}\right)}
$$

where $g_{\max (T)}$ is the response of leaf conductance when it is maximal due to low $\Delta \mathrm{w}$ and to leaf temperature.

The relationship between leaf conductance and $\Delta \mathrm{w}$ was described as a 'feedforward' response (Farquhar 1978) as follows:

$$
g_{(\Delta w)}=\left[g_{0}-\left(g^{*} / \Delta w^{*}\right) \Delta w\right] /\left[1-\left(2-g_{0} / g^{*}\right) \Delta w / \Delta w^{*}\right],
$$


where $\Delta w^{*}$ is the leaf-air water vapor concentration difference at which transpiration is maximal, and $\mathrm{g}^{*}$ is the corresponding leaf conductance. For the determination of $\Delta \mathrm{w}^{*}$, a regression of the type:

$$
g_{(\Delta w)^{-1}}=e^{\left(b_{3} \Delta w+b_{4}\right)}
$$

was determined. Extrapolation to $\Delta \mathrm{w}=0$ yielded $\mathrm{g}_{\mathrm{O}}$. The position of maximal transpiration is given by $\Delta w^{*}=b_{3}{ }^{-1}$. Thus $g^{*}$ can be determined and with it Eq. 39 can be solved.

The two submodels can be linked at any given combination of light and temperature as follows:

$$
g_{(I, T)}=\left[\left[g_{\max (T)}-g_{(A=0, T)}\right] A_{(I, T)} / A_{\max (T)}\right]+g_{(A=0, T)}
$$

where $\mathrm{g}_{(\mathrm{A}=0, \mathrm{~T})}$ is the leaf conductance at light compensation for $\mathrm{CO}_{2}$ uptake. It was found that $g_{(A=0, T)}$ was linearly related to $g_{\max }(T)$ and could be parameterized as:

$$
g_{(A=0, T)}=p g_{\max (T)}
$$

The relationship between assimilation and conductance is given by:

$$
A=\left(C_{a}-C_{i}\right) g_{\Delta w} / 1.6(1000),
$$

where $\mathrm{C}_{\mathrm{a}}$ is ambient $\mathrm{CO}_{2}$, and $\mathrm{C}_{\mathrm{i}}$ is the internal $\mathrm{CO}_{2}$ concentrations. The factor 1.6 accounts for the difference of diffusivities between $\mathrm{H}_{2} \mathrm{O}$ and $\mathrm{CO}_{2}$ while the factor 1000 corrects for units. With rearrangement $C_{i}$ is predicted by: 


$$
\mathrm{C}_{\mathrm{i}}=\mathrm{C}_{\mathrm{a}}-1.6(1000) \mathrm{A} / \mathrm{g}_{\Delta \mathrm{w}}
$$

For different leaf temperatures and light levels it was assumed that the relative response of stomata to humidity did not vary. Likewise, a similar limitation of $\mathrm{CO}_{2}$ assimilation due to stomata was assumed for the same $\Delta \mathrm{w}$, but different temperatures and light levels.

This model predicted diurnal assimilation, $\mathrm{C}_{\mathrm{i}}$, transpiration, and leaf conductance very well for Pinus sylvestris (Figure 5) using the parameters in Table 8.

TABLE 8. Parameters for Equations in the Model of Kuppers and Schulze (1985).

\begin{tabular}{|c|c|c|}
\hline Parameters & $\begin{array}{l}\text { Parameter } \\
\text { values }\end{array}$ & Units \\
\hline$a_{1}$ & $-1.72 \times 10^{-3}$ & $\mathrm{~m}^{2} \mathrm{~s} \mu \mathrm{mol}^{-1}$ \\
\hline$a_{2}$ & $-1.013 \times 10^{-4}$ & $\mu \mathrm{mol} \mathrm{m} \mathrm{m}^{-2} \mathrm{~s}^{-1{ }^{\circ}} \mathrm{C}^{-3}$ \\
\hline$a_{3}$ & $2.168 \times 10^{-3}$ & $\mu \mathrm{mol} \mathrm{m} \mathrm{m}^{-2} \mathrm{~s}^{-1{ }^{\circ}} \mathrm{C}^{-2}$ \\
\hline$a_{4}$ & 0.0523 & $\mu \mathrm{mol} \mathrm{m}-2 \mathrm{~s}^{-1 \circ} \mathrm{C}^{-1}$ \\
\hline$a_{5}$ & 0.216 & $\mu \mathrm{mol} \mathrm{m}-2 \mathrm{~s}^{-1}$ \\
\hline$a_{6}$ & 0.147 & ${ }^{\circ} \mathrm{C}^{-1}$ \\
\hline$a_{7}$ & 1.787 & dimensionless \\
\hline$a_{8}$ & $0.8754 \times 10^{-3}$ & $\mu \mathrm{mol} \mathrm{m}{ }^{-2} \mathrm{~s}^{-1{ }^{\circ}} \mathrm{C}^{-2} 9$ \\
\hline ag & 2.052 & dimensionless \\
\hline$b_{1}$ & 0.083 & ${ }^{\circ} \mathrm{C}^{-1}$ \\
\hline$b_{2}$ & 3.209 & dimensionless \\
\hline$g_{0}$ & 133.8 & $\mathrm{mmol} \mathrm{m} \mathrm{s}^{-2}$ \\
\hline $\mathrm{g}^{*}$ & 49.2 & $\mathrm{mmol} \mathrm{m}^{-2} \mathrm{~s}^{-1}$ \\
\hline$\Delta w^{*}$ & 31.8 & mbar bar ${ }^{-1}$ \\
\hline p & 0.66 & dimensionless \\
\hline
\end{tabular}





FIGURE 5. Test of the Model for the Natural Daily Course of Climate (Adapted from Kuppers and Schulze 1985). 
Model of Avissar (Avissar et al. 1985)

The previously described model of Kuppers and Schulze (1985) is very accurate, but is perhaps somewhat involved. It also does not include the effect of water potential on stomatal conductance. The model of Avissar et al. (1985) includes a relationship between soil water potential and stomatal conductance in addition to the effects of vapor pressure deficit, temperature, and light. It is simpler and does not consider assimilation. It also is not quite as accurate, but may be acceptable. Their model relates stomatal conductance to solar global radiation, leaf temperature, vapor pressure gradient, ambient $\mathrm{CO}_{2}$, and soil water potential for Nicotiana tabacum.

The general equation used to predict relative stomatal conductance is as follows:

$$
\begin{aligned}
& d_{T s}=\left[d_{s m}+\left(d_{s M}-d_{s m}\right) f_{R} f_{T} f_{V} f_{C} f_{P}\right] / d_{s M} \\
& \text { Where: } \mathrm{d}_{\mathrm{rs}}=\text { the relative stomatal conductance }\left(\mathrm{ms}^{-1} / \mathrm{ms}^{-1}\right) \text {, } \\
& \mathrm{d}_{\mathrm{Sm}}=\text { the minimal conductance which occurs through } \\
& \text { the leaf cuticle when the stomata are closed, } \\
& \mathrm{d}_{\mathrm{SM}}=\text { the inaximal stomatal conductance obtained when } \\
& \text { stomata are completely opened, and } \\
& \mathrm{f}_{\mathrm{i}}=\text { functions of the influence of a specific } \\
& \text { environmental factor upon the conductance ( } R \text { for } \\
& \text { solar global radiation, } T \text { for leaf temperature, } V \text { for } V P D, C \text { for air } \\
& \mathrm{CO}_{2} \text { concentration, and } \mathrm{P} \text { for soil water potential). }
\end{aligned}
$$

The mathematical expression used for each of the $f_{i}$ functions is as follows:

$$
f_{i}=1 /\left\{1+e^{\left[-S\left(X_{i}-b\right)\right]}\right\}
$$




$$
\text { Where: } \begin{aligned}
\mathrm{i} & =\text { the environmental factor, } \\
\mathrm{b} & =\text { the abscissa at } \mathrm{f}_{\mathrm{i}}=1 / 2, \\
\mathrm{~S} & =\text { the slope of the curve at this point, and } \\
\mathrm{X}_{\mathrm{i}} & =\text { the intensity of the factor } \mathrm{i}
\end{aligned}
$$

To use this model $d_{s m}, d_{s M}, b$, and $S$ must be determined. In their experiment $d_{s m}=$ $0.05 \mathrm{~cm} \mathrm{~s}^{-1}$ and $d_{s M}=0.93 \mathrm{~cm} \mathrm{~s}^{-1}$. Values for $\mathrm{b}$ and $\mathrm{S}$ are found in Table 9 .

TABLE 9. Values of $b$ and $\mathbf{S}$ for Functions of Stomatal Response to Environmental Factors.

Environmental factor

Global radiation

$\mathrm{CO}_{2}$ concentration $\mathrm{ppm}$

Temperature

(cool range)

Temperature

(warm range)

Vapor pressure

difference

Soil water

potential
Units

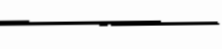

$\mathrm{W} \mathrm{m} \mathrm{m}^{-2}$

3.5

$\infty$

${ }^{\circ} \mathrm{C}$

8.9

0.41

${ }^{\circ} \mathrm{C}$

34.8

$-1.18$

$\mathrm{Pa}$

2860

$-0.0031$

$\mathrm{Pa}$

S

0.034

Pa

$0.25 \times 10^{-5}$ 


\section{Model of Hicks (Hicks et al. 1985)}

The model of Hicks et al. (1985) previously discussed as it applied to atmospheric processes, is more comprehensive than the previously described models in that it attempts to infer dry deposition based on micrometeorology and includes an in-depth analysis of the role of plants from single leaf to canopy processes. In this section we present their approach to modeling the plant component. They call the plant component canopy resistance where stomatal, mesophyll, and cuticular resistances are considered. In this section we will focus on stomatal resistance to gaseous xenobiotics. They recognize the importance of plant phenology and the effects that tissue age has on stomatal resistance, but do not develop these factors in their model. Their stomatal resistance model is functionally related to photosynthetically active radiation (PAR), air temperature, and humidity. They extend this model for single leaves based on leaf area to resistances expressed per unit area of the earth's surface via the leaf area index (LAI).

The model relates stomatal resistance to light (Burrows and Milthorpe 1976) as:

$$
\begin{aligned}
& \mathrm{r}_{\mathrm{S}}=\mathrm{r}_{\mathrm{Sm}}\left(1+\left(\mathrm{b} / \mathrm{I}_{\mathrm{p}}\right)\right)=\mathrm{g}_{\mathrm{s}}^{-1} \\
& \text { Where: } \quad \mathrm{r}_{\mathrm{S}}=\text { stomatal resistance }\left(\mathrm{s} \mathrm{m}^{-1}\right) \\
& \mathrm{r}_{\mathrm{Sm}}=\text { minimal stomatal resistance, } \\
& \mathrm{I}_{\mathrm{p}}=\text { the level of PAR, } \\
& \mathrm{b}=\text { an empirical constant, and } \\
& \mathrm{g}_{\mathrm{S}}=\text { stomatal conductance. }
\end{aligned}
$$

They further relate stomatal conductance to vapor pressure deficit, leaf water potential, and temperature by scaling these effects between 0 and 1 and multiplying their multiple with the light response. The light response is developed at optimal conditions of 
vapor pressure deficit, leaf water potential, and temperature. This method follows that of Jarvis (1976) and is similar to that used in Avissar et al. (1985).

The reduction of stomatal conductance with increasing vapor pressure deficit is written as a scaling factor as:

$$
f_{e}=1-b_{e} v p d
$$

Where: $f_{e}=$ the scaling factor,

$$
\mathrm{b}_{\mathrm{e}}=\text { the slope, and }
$$$$
\text { vpd }=\text { the vapor pressure deficit. }
$$

A piece-wise relationship is used (Fisher et al. 1981) to relate stomatal conductance to leaf water potential as follows:

$$
\begin{aligned}
& \mathrm{f}_{\mathrm{w}}=1, \text { if } \mathrm{P}>\text { threshold, } \\
& \mathrm{f}_{\mathrm{w}}=\mathrm{a} \mathrm{P}+\mathrm{b}, \text { if } \mathrm{P}<\text { threshold, }
\end{aligned}
$$

where $P$ is the leaf water potential and $a$ and $b$ are constants.

The effect of temperature on stomatal conductance is written as:

$$
\begin{aligned}
& \mathrm{f}_{\mathrm{T}}=\left\{\left[\left(\mathrm{T}-\mathrm{T}_{1}\right) /\left(\mathrm{T}_{\mathrm{o}}-\mathrm{T}_{1}\right)\right]\left[\left(\mathrm{T}_{\mathrm{h}}-\mathrm{T}\right) /\left(\mathrm{T}_{\mathrm{h}}-\mathrm{T}_{\mathrm{o}}\right)\right]\right\}^{\mathrm{b}_{\mathrm{T}}} \\
& \text { Where: } \quad{ }^{\mathrm{b}_{\mathrm{T}}}=\left(\mathrm{T}_{\mathrm{h}}-\mathrm{T}_{\mathrm{o}}\right) /\left(\mathrm{T}_{\mathrm{h}}-\mathrm{T}_{1}\right)
\end{aligned}
$$

Here, $T_{h}$ and $T_{1}$ are high and low temperature limits at which stomata are no longer open, and $\mathrm{T}_{\mathrm{o}}$ is the optimal temperature for stomatal conductance. 
The final equation for predicting stomatal conductance is given as:

$$
g_{s}=r_{s m}{ }^{-1}\left(1+b / I_{p}\right)^{-1} f_{e} f_{w} f_{T} .
$$

Hicks et al. (1985) then compute a canopy resistance by scaling with the leaf area index. They comment that this simple approach is adequate for small plants, but is inaccurate for large plants because of internal canopy shading.

\section{ABIOTIC AND BIOTIC FACTORS CONTROLLING STOMATAL CONDUCTANCE}

Most models of stomatal conductance consider, at most, only a few of the environmental or biological factors which control stomatal aperture. Most models are specific for the conditions of the experiment, such as the time of year or growing conditions, and are not easily extended to other conditions. We have not been able to find models which can predict stomatal conductance taking into account all the important controlling factors. Such a model would be able to predict stomatal conductance through the life span or a whole growing season for various abiotic and biotic conditions. This kind of model would be valuable relative to the assessment of the internal concentrations of gaseous xenobiotics in general. In addition to natural variation in stomatal conductance the effect of various xenobiotics on stomatal conductance itself would be valuable in the more precise prediction of internal xenobiotic concentrations. The importance of stomatal conductance for the prediction of the uptake of gaseous xenobiotics requires a best attempt at the prediction of stomatal conductance for a wide variety of conditions. Therefore, in addition to the review of models for the prediction of internal xenobiotic concentrations, we present a review of factors which control stomatal conductance.

The most important environmental factors which control stomatal conductance are light intensity, light quality, $\mathrm{CO}_{2}$ concentration, temperature, humidity, wind speed, soil nutrient status, and leaf water potential. 
The response of stomatal conductance to the intensity of white light is a saturation type with conductance increasing rapidly with initial increments of light and leveling off at higher hight intensities. The exact form of the relationship is dependent on the species and other factors which control conductance (Hsiao 1975).

Stomatal opening responses are most responsive to light in the blue portion of the spectrum with a peak of action extending from 420 to $460 \mathrm{~nm}$ and no action $>560 \mathrm{~nm}$. Stomata will respond to this light at low intensities (Raschke 1975). Light in the green portion of the spectrum elicits an opening response only at high intensities (Farquhar and Sharkey 1982).

Stomata tend to operate to maintain internal $\mathrm{CO}_{2}$ constant (Raschke 1975) opening as internal concentrations drop and closing as concentrations increase (Sheriff 1979). Stomata also close at high external $\mathrm{CO}_{2}$ concentrations (Hsiao 1975). Closure at high $\mathrm{CO}_{2}$ concentrations is mentioned because it can be unintentionally introduced in experimentation by breathing (Heath and Mansfield 1962). Experiments to define stomatal conductance relationships under natural conditions do not require the experimental variation of external $\mathrm{CO}_{2}$ concentrations and care must be taken to maintain $\mathrm{CO}_{2}$ at ambient levels during experimentation. Monitoring $\mathrm{CO}_{2}$ levels is done by infrared gas analysis.

The most common form of relationship between temperature and stomatal conductance is one with increasing conductance to a broad optimum and then declining with increasing temperature (Hsiao 1975; Avissar et al. 1985). Other relationships have been observed: decreasing, increasing, or no relationship with temperature (Sheriff 1979). 
A direct relationship between the vapor pressure gradient and stomatal conductance was conclusively demonstrated by Lange et al. (1971) and termed a 'feedforward' stomatal response (Cowan 1977). The general form of the relationship is a linearly (Warrit et al. 1980), exponentially (Roessler and Monson 1985), or 'threshold type' (Avissar et al. 1985) decreasing function with increasing vapor pressure deficit depending on species and conditions.

Stomatal closure is induced by bulk leaf water stress in a 'feedback' response (Cowan 1977) and the form of the relationship is generally found to be a 'threshold type' response (Avissar et al. 1985) with decreasing leaf water potential.

Wind speed influences stomatal conductance. Some species respond to increasing wind speed with stomatal closure and some with stomatal opening (Caldwell 1970; Kramer 1983). These responses are attributed to changes in humidity near the leaf due to changes in the boundary layer (Sheriff 1979) or changes in the internal $\mathrm{CO}_{2}$ concentration (Meidner and Mansfield 1968).

Reductions in stomatal conductance have been observed with deficiencies in a wide variety of soil nutrients and in particular; nitrogen, phosphorus, and potassium (Sheriff 1979).

Plants also respond to stressful conditions of temperature and water status by 'hardening' to the conditions. Adjustment in stomatal conductance is one manifestation of 'hardening' in response to stress ( Turner and Kramer 1980).

The major biotic factors which control stomatal conductance are physiological leaf age and hormones. The responsiveness of stomata depends on the physiological age of the leaf. Stomata of older leaves of some species do not open as rapidly or as widely as in younger leaves (Hsiao 1975; Kramer 1983). Tazaki et al. (1980) found that the stomata of older mulberry leaves would not close. The hormone, ABA, has been found to induce stomatal closure usually in association with water stress (Kramer 1983). In some plants 
stomatal closure is not correlated with ABA levels (Ackerson 1980), but may be related to other substances such as farnesol (Mansfield et al. 1978) and phaseic acid (Sharkey and Raschke 1980). Cytokinins cause stomatal opening and also retard senescence (Farquhar and Sharkey 1982); this may be related to the observed effect of leaf age on stomatal conductance.

It is important to realize that gaseous xenobiotics can also affect stomatal conductance and thus influence transport into the apoplast. Stomatal conductance may either increase (Biscoe et al. 1973; Jensen and Roberts 1986) or decrease (Winner and Mooney 1980; Jensen and Roberts 1986) with exposure to $\mathrm{SO}_{2}$. Ozone generally elicits a reduction in stomatal conductance (Winner and Atkinson 1986) although this is in part caused by decreased assimilation tates in $\mathrm{O}_{2}$ damaged leaves which affects $\mathrm{C}_{\text {internal }}$. Peroxyacetyl nitrate causes a reduction in stomatal conductance in Phaseolus vulgaris (Metzler and Pell 1980). Nitrogen dioxide does not cause a reduction in stomatal conductance in Helianthus annuus or Zea mays (Okano et al. 1986).

\section{Diffusion of Water Vapor to Infer the Diffusion of Qther Gases}

It is generally accepted that the diffusivity of gases other than water vapor can be taken as a ratio of water in resistance models, as stomatal conductance models are usually based on the diffusion of water. For instance $\mathrm{CO}_{2}$ resistance is taken as 1.6 times $\mathrm{H}_{2} \mathrm{O}$ resistance. This assumption has been questioned for diffusion within the internal air spaces of the leaf. This is because it has been shown that the pathlength within the leaf for $\mathrm{CO}_{2}$ is much longer than that of $\mathrm{H}_{2} \mathrm{O}$ (Cooke and Rand 1980). Most of the water evaporates in the substomatal cavity while $\mathrm{CO}_{2}$ diffuses throughout the internal air spaces coming in contact with the mesophyll cells (Aston and Jones 1976). Recent research with $\mathrm{SO}_{2}$ (Taylor and Tingey 1983; and Olszyk and Tingey 1985) and $\mathrm{O}_{3}$ (Taylor et al. 1982; Tingey and Taylor 1982) further question the assumption that the pathlength for these air pollutants and water vapor are the same. They have shown that the pathlengths are not 
the same and that this explains much of the variability in previous reports. This observation has serious consequences for resistance models using the diffusivity of water vapor as a basis to compute the flux of other gases.

\section{Stomatal Parameters}

The number, distribution, size, shape, and mobility of stomata are species-specific and can vary with habitat and among individuals (Table 10). The opening capacity of stomata is the greatest in herbaceous dicotyledons, in deciduous trees with open crowns, and in tropical trees. It is the lowest in woody plants with sclerophyllous leaves (Larcher 1980).

\section{Molecular Diffusivity of Gases in Air}

Tingey and Taylor (1982) provide information (Table 11) relating the diffusivity of various gaseous air pollutants to the diffusivity of $\mathrm{H}_{2} \mathrm{O}$. The molecular diffusivity, $\mathrm{D}$, of a gas in air depends on temperature $\left(\mathrm{T}^{\circ} \mathrm{K}\right)$, pressure $(\mathrm{kPa})$, and atomic size (Jarvis 1971). The dependencies of temperature and pressure are represented by:

$$
\mathrm{D}(\mathrm{T}, \mathrm{P})=\mathrm{D}(\mathrm{Tr}, \mathrm{Pr})(\mathrm{T} / \mathrm{Tr}) 1.75(\mathrm{Pr} / \mathrm{P})
$$

where $T_{r}$ is a reference temperature $\left(293^{\circ} \mathrm{K}\right)$, and $P_{r}$ is a reference pressure $(101.3$ $\mathrm{kPa}$ ). The values in Table 11, as calculated in Tingey and Taylor (1982), were based on a temperature of $293^{\circ} \mathrm{K}$ and air pressure of $101.3 \mathrm{kPa}$ and are relative to the diffusivity of water vapor $\left(\mathrm{D}_{\mathrm{H} 2 \mathrm{O}}=24 \mathrm{~mm}^{2} \mathrm{~s}^{-1}\right)$ assuming that:

$$
\mathrm{D}(\mathrm{M})=\mathrm{D}_{\mathrm{H}_{2} \mathrm{O}}\left(\mathrm{M}_{\mathrm{H}_{2} \mathrm{O}} \mathrm{O}^{1 / 2}\right.
$$

where $\mathrm{M}$ is the molecular weight (Unsworth et al. 1976). 
TABLE 10. Stomatal Density, Pore Length, and Pore Width on the Adaxial (lower) Side of Leaves, with the Minimal Stomatal Diffusion Resistance for $\mathrm{CO}_{2}$ (computed for one side of the leaf). Adapted from Larcher (1980).

\begin{tabular}{|c|c|c|c|c|}
\hline Plants & $\begin{array}{l}\text { Stomatal } \\
\text { density } \\
\text { (number } \\
\text { per mm }{ }^{2} \\
\text { leaf area) }\end{array}$ & $\begin{array}{l}\text { Pore } \\
\text { length } \\
(\mu \mathrm{m})\end{array}$ & $\begin{array}{l}\text { Maximal } \\
\text { pore width } \\
(\mu \mathrm{m})\end{array}$ & $\begin{array}{l}\text { Minimal } \\
\text { stomatal } \\
\text { diffusion } \\
\text { resistance to } \\
\mathrm{CO}_{2}\left(\mathrm{~s} \mathrm{~cm}^{-1}\right)\end{array}$ \\
\hline $\begin{array}{l}\text { Herbaceous } \\
\text { plants of } \\
\text { sunny habitats }\end{array}$ & $\begin{array}{l}100-200 \\
(300)\end{array}$ & $10-20$ & $4-5$ & $0.6-2.6$ \\
\hline $\begin{array}{l}\text { Herbaceous } \\
\text { plants of } \\
\text { shady habitats }\end{array}$ & $\begin{array}{l}40-100 \\
(150)\end{array}$ & $15-20$ & $5-6$ & $2.2-6.5$ \\
\hline Grasses & $\begin{array}{l}50-100 \\
(30)\end{array}$ & $20-30$ & ca. 3 & $0.9-5.2$ \\
\hline Palm trees & $150-180$ & $15-24$ & $2-5$ & ca. 6 \\
\hline Tropical trees & $200-600$ & $12-24$ & $3-8$ & - \\
\hline Forest trees & $(900)$ & & & \\
\hline Winter trees & $100-500$ & $7-15$ & $1-6$ & $1.7-6.5$ \\
\hline $\begin{array}{l}\text { Sclerophyllous } \\
\text { plants }\end{array}$ & $\begin{array}{l}100-500 \\
(1000)\end{array}$ & $10-15$ & $1-2$ & $1.7-5.2$ \\
\hline Conifers & $40-120$ & $15-20$ & - & $2.0-6.5$ \\
\hline Desert shrubs & $150-300$ & $10-15$ & - & $1.6-6.5$ \\
\hline Succulents & $\begin{array}{l}15-50 \\
(100)\end{array}$ & ca. 10 & ca. 10 & 3.1 .6 .5 \\
\hline
\end{tabular}


TABLE 11. Characteristics of Various Air Pollutants. (From Tingey and Taylor 1982).

\begin{tabular}{|c|c|c|c|}
\hline Gas & $\begin{array}{l}\text { Molecular Weight } \\
\left(\mathrm{g} \mathrm{mol}^{-1}\right)\end{array}$ & $\begin{array}{l}\text { Density } \\
\left(\mathrm{kg} \mathrm{m}^{-3}\right)\end{array}$ & $\begin{array}{l}\text { Diffusivity in air } \\
\left(\mathrm{mm}^{2} \mathrm{~s}^{-1}\right)\end{array}$ \\
\hline Ammonia $\mathrm{NH}_{3}$ & 17.0 & 0.72 & 25 \\
\hline Chlorine $\mathrm{Cl}_{2}$ & 70.9 & 2.99 & 12 \\
\hline Ethylene $\mathrm{C}_{2} \mathrm{H}_{4}$ & 28.0 & 1.17 & 19 \\
\hline Fluorine $F_{2}$ & 38.0 & 1.58 & 16 \\
\hline Hydrogen chloride $\mathrm{HCl}$ & 36.5 & 1.53 & 17 \\
\hline Hydrogen fluoride $\mathrm{HF}$ & 20.0 & 0.83 & 23 \\
\hline Hydrogen sulfide $\mathrm{H}_{2} \mathrm{~S}$ & 34.1 & 1.43 & 18 \\
\hline Nitric oxide NO & 30.0 & 1.25 & 18 \\
\hline Nitrogen dioxide $\mathrm{NO}_{2}$ & 46.0 & 1.88 & $15\left(\mathrm{~T}=298^{\circ} \mathrm{K}\right)$ \\
\hline Ozone $\mathrm{O}_{3}$ & 48.0 & 1.99 & 15 \\
\hline $\begin{array}{l}\text { Peroxlacetyl nitrate } \\
\left.\left(\mathrm{PAN}-\mathrm{CH}_{3} \mathrm{COONO}\right)_{2}\right)\end{array}$ & 105.0 & - & 10 \\
\hline Sulfur dioxide $\mathrm{SO}_{2}$ & 64.1 & 2.73 & 12 \\
\hline
\end{tabular}




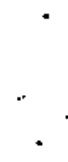




\section{CONCLUSIONS AND RECOMMENDATIONS}

The principal objective of this assessment was to review existing mathematical and/or computer simulation models that are used to estimate the following:

1. aerial deposition (wet and dry) of xenobiotics to plants,

2. foliar/cuticular transport of organic xenobiotics, and

3. stomatal transport of gaseous and volatile organic xenobiotics.

The second objective was to provide sufficient detail to determine the potential for adapting or coupling the best of those models evaluated to the existing UTAB (Uptake, Translocation, Accumulation, and Biodegradation) plant exposure model. Presently, the soil/plant based UTAB model (McFarlane 1986) is designed to characterize and quantify the storage/metabolism components, transport/mobility behavior, and accumulation patterns of xenobiotics following root absorption in plants. Extension of this model to include the rates of xenobiotic deposition and transport to the apoplastic canopy surfaces from the air column, and subsequent transfer to the leaf symplast and leaf phloem, represents an interfacing of five models. In addition to the UTAB model, fully parameterized Source Term, Aerial Deposition (Wet and Dry), Foliar/Cuticular, and Stomatal Models will be required (Figure 6).

Based only on the literature evaluation, summarized in the conclusions and recommendations provided below, mathematical linking of these models is possible; however, the immediate utility of this "master" model would be questionable. The inability to adequately link these models results from either 1) a lack of empirical data for specific types of xenobiotics, and/or 2) a lack of detailed understanding of controlling processes. Of the four models requiring linkage to the UTAB model, Wet and Dry Deposition are the best parameterized. Assuming that an order of magnitude precision is acceptable, these models can be used to predict the transfer coefficients for a range of both gaseous and particulate xenobiotics to the surfaces of canopies. Similarly, 


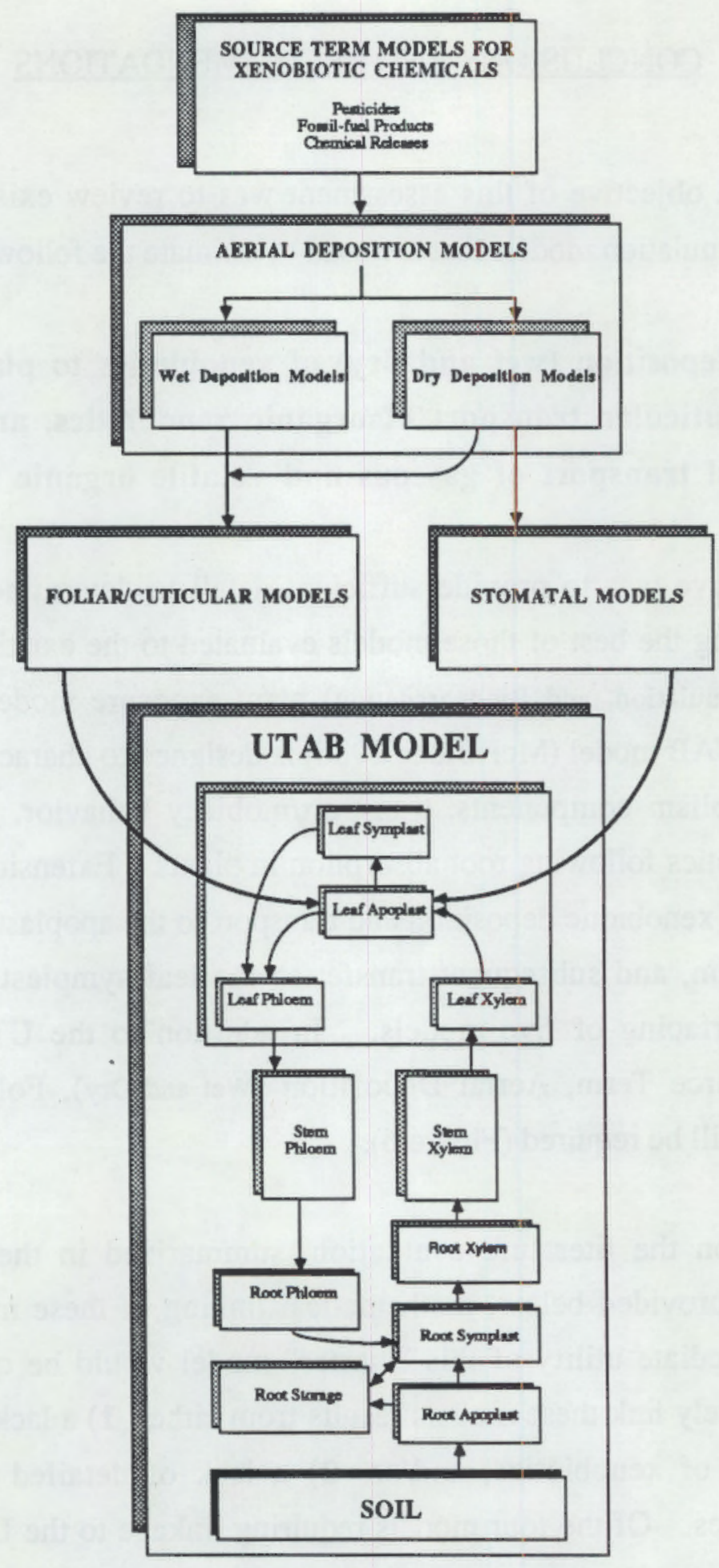

FIGURE 6. Linkage of Source Term, Aerial Deposition, Foliar/Cuticular, and Stomatal Models with the EPA UTAB Model. 
stomatal models are presently suitable for estimation of gross absorbed dose for gases, but fall far short in the case of volatile organics. Foliar/Cuticular models, although conceptually acceptable, suffer from a severe lack of specific data on a large enough range of xenobiotic compounds, and presently can not provide even two orders of magnitude precision.

In addition to the stated problems with model linkage to UTAB, the most severe limitation is the mathematical simulation of the transfer of xenobiotics from apoplastic surfaces to the symplast where UTAB picks up (see Figure 6). The processes which affect the chemical behavior and fate of inorganic, and particularly organic residues, while associated with the apoplast, are presently unclear. In the case of charged inorganic species and polar organics, transfer from apoplast to symplast will undoubtedly be controlled by membrane transport and affinity, with sorption to charge sites and chemical stability being mediating factors. In the case of non-polar residues, lipid solubility will dominate as far as transfer, while the dose component of the flux equation will be influenced by rates of apoplastic diffusion and vapor pressure of the xenobiotic.

\section{AERIAL DEPOSITION MODELS}

The objective of computing xenobiotic chemical deposition to plant surfaces is to provide source terms for both the foliar/cuticular and stomatal model (see Figure 6). However, in order to compute that deposition accurately the model will need to consider the properties of the material, the chemical makeup of the receptor surface, and ambient amospheric conditions. As described earlier, the processes controlling that deposition can be broadly divided into wet and dry; each process is distinct in its actions, and as noted earlier requires different models.

\section{Wet Deposition Models}

The atmospheric removal component of a wet deposition model requires defimition of the physical and chemical properties of each xenobiotic material. We feel the best 
model available for adaption to the EPA UTAB model is PLUVIUS as described by Easter and Hales (1984). However, this will require estimates of in-cloud and under-cloud xenobiotic air concentrations, cloud characteristics, precipitation characteristics, and collection efficiencies. Scavenging models other than PLUVIUS are either very simple generic computations of average deposition rates based on gross properties, or detailed case study computational models for a specific material in a particular set of conditions.

\section{Dry Deposition Models.}

The best dry deposition (particles and gases) models for interface with the chosen foliar/cuticular and stomatal models are presented in Bache (1986), Winman (1985), Winman and Agren (1986), and Van Voris et al. 1985. However, these dry deposition

models require a general definition of the properties of each xenobiotic material. The time of day, cloud cover, time of year, wind speed, etc., all need to be considered in terms of their influence on the dry deposition rate. The atmospheric resistance can be computed relatively easily assuming certain ideal conditions. The modeling of other resistance terms is more difficult, and for many applications is a topic of current research efforts. Reasonable estimates of deposition rates on low canopies should be possible. The deposition estimates from models for deposition on higher canopies will be less certain.

\section{FOLIAR/CUTICULAR MODELS}

While a substantial data base exists on actual and mathematically simulated behavior of gaseous pollutants, there are many unanswered questions concerning the cuticular transport of organic residues. This produces a weak link in interfacing and coupling atmospheric transport models with the UTAB model. The conclusions/recommendations which follow are based on our literature review alone and do not include experimental data. 
I. No single model reviewed from the open literature was found to completely encompass the requested parameterizations for the UTAB model of physical binding and chemical reactions such as vapor pressure, solubility, and molecular size, charge, and energy.

- Although most models of cuticular transport are based on Fick's First Law of diffusion there exists wide variation in the definitions of terms comprising the basic equation.

- This produces corresponding differences in the available estimates of transport coefficients (compare Table 3 with Table 7).

- It further appears that much of this variability arises from a lack of specific knowledge of cuticular structure and chemical composition and its effects on permeability/transport.

II. Of those mathematical descriptions of cuticular transport which are currently available, the ongoing work of Schönherr and Reiderer (particularly Reiderer and Schönherr, 1984, 1985 and 1986) may prove to be the most quantitative and potentially transposable to the UTAB model.

- They have established experimental procedures for the quantitative determination of permeance coefficients based on both the diffusive and partitioning ability of the compound in question.

- They have also attempted to determine variations between a limited number of species (10) as well as between types of cuticles (i.e., fruits vs. leaves) (see Tables 4-7). 
- However, they have only studied a very limited number of compounds (primarily 2,4-D), under strictly controlled environmental conditions, and they further admit that their current estimate for $2,4-\mathrm{D}$ is only within an order of magnitude of the probable actual value.

- The list of compounds to be quantitated in this manner must be extended in order to validate the equations for application to the UTAB model.

III. Prior to enlarging the selection of compounds there is a critical need to establish a priority for those compounds or compound classes for which there is a real or perceived environmental and/or health risk.

- This is essential in reducing the myriad of potential organic residues entering the environment to a manageable number.

- A serious selection of representative compounds, varying in chemistry and degree of substitution is recommended based on the limited data available.

Once such a list is produced, characterizations can proceed as recommended above to provide data for application to developed models.

Again, valid extrapolation of available models and the quantitative values generated by them to the UTAB model would be very tenuous at this time. We believe however, that application of the experimental approaches of Schönherr (1978-82) and Reiderer et al. (1984-86) to additional compounds and species would yield data transposable to equations for the UTAB and other models. In order to achieve this in a reasonable period of time a prioritization of potential compounds and /or classes of compounds is essential. 


\section{STOMATAL MODELS}

The point of interface of stomatal models with the UTAB model is in the apoplast. The UTAB model requires that xenobiotic concentrations in the apoplast be predictable. This is possible with current stomatal models as a first approximation for special cases. The modeling approach of Hicks et al. (1985) is recommended chiefly because the stomatal portion of the model is well integrated into their overall model of dry deposition of xenobiotics. They also provide the computer code for ease of implementation.

I. Accuracy of apoplastic estimates.

- Recent work has called into question the use of the assumption that the diffusion of gaseous xenobiotics can be based on the diffusion of water (see pages 62-63). Further investigations on this line of research are needed to improve our models of diffusion processes.

- The use of stable isotopes coupled with split-chamber gas exchange research should help improve estimates of apoplastic xenobiotic concentrations.

II. Generalization of apoplastic estimates.

- Much work needs to be done to more accurately predict stomatal conductance as a function of abiotic and biotic factors as discussed in the body of the report (see pages 59-61). It will be important to predict stomatal conductance through the life cycle or the growing season for a wide variety of species to better understand how they interact with various xenobiotics. Plant growth models have recently been reviewed by Reynolds and Acoch (1985) and the reader is referred there for information on matters of growth and spatial scale 
- To understand how xenobiotics interact with plants at the canopy level is a natural extension of understanding at the single leaf level. Unfortunately this is difficult, but important relative to accurate estimation to the apoplast concentration. It is possible to integrate single leaf behavior to yield an estimate of whole plant behavior, but this approach requires a great deal of data and complex models. Alternatively, plant behavior can be assessed at the whole plant level with whole plant gas exchange. This approach becomes technically difficult for large plants (i.e., trees), but has been done for shrubs and smaller plants.

The estimation of apoplastic xenobiotic concentrations with stomatal models is currently possible. Further research is needed to inake more accurate estimates and to generalize these estimates. 


\section{REFERENCES}

Ackerson, R. C. 1980. Stomatal response of cotton to water stress and abscisic acid as affected by water stress history. Plant Physiol 48:631-636.

Ashton, F.M., and A.S. Crafts. 1981. Mode of Action of Herbicides. John Wiley and Sons, New York.

Aston, J. J., and M.M. Jones. 1976. A study of the transpiration surfaces of Avena sterilis L. var Algerian leaves using monosilicic acid as a tracer for water movement. Planta 130:121-134.

Avissar, R., P. Avissar, Y. Mahrer, and B.A. Bravdo. 1985. A model to simulate response of plant stomata to environmental conditions. Agricultural and Forest Meteor, 34:21-29.

Bache, D. H. 1986. On the theory of gaseous transport to plant canopies, Atmos, Environ. 20 (7): 1379-1388.

Baker, E.A. 1980. Effect of cuticular components on foliar penetration. Pestic. Sci. 11:367-370.

Baker, E.A. 1982. Chemistry and morphology of plant epicuticular waxes. In The Plant Cuticle. eds. DF Cutler, KL Alvin, and CE Price., Academic Press, New York. pp.139-165.

Bennett, J. A., A.C. Hill, and D.M. Gates. 1973. A model for gaseous pollutant sorption by leaves. L Air Pollut. Control Ass, 23:957-962.

Beste, C.E. 1983. Herbicide Handbook, Weed Science Society of America, Champaign, Ill.

Bird, R.B., W.E. Stewart, and E.N. Lightfoot. 1960. Transport Phenomena. John Wiley and Sons, Inc. New York

Biscoe, P. V., M.H. Unsworth, and H.R. Pinckney. 1973. The effects of low concentrations of sulphur dioxide on stomatal behavior in Vicis faba. New Phytol. 72:1299-1306.

Boyer, J .S. 1985. Water transport. Ann. Rey, Plant Physiol. 36:473-516.

Brown, H., and F. Escombe. 1900. Static diffusion of gases and liquids im relation to the assimilation of carbon and translocation in plants. Phil. Trans. Roy. Soc. London. Ser. B. 193:223-291 
Burrows, F. J., and F.L. Milthorpe. 1976. Stomatal conductance in the control of gas exchange. In Water Deficits and Plant Growth Vol. 4.: 103-152. ed. T.T. Kozlowski Academic Press. New York

Businger, J. A., J. C. Wyngaard, Y. Izumi, and E. F. Bradley. 1974. Flux profile relationships in the atmospheric surface layer, J, Atmos. Sci. 28, 181-189.

Caldwell, M. M. 1970. The effect of wind on stomatal aperature, photosynthesis, and transpiration of Rhododendron ferrigineum $\mathrm{L}$. and Pinus cembra L. Centralblatt fur das Gesamt Fortwesen 87:193-201.

Casterline, J.L., N.M. Barnett, and Y. Ku. 1985. Uptake, translocation and transformation of pentachlorophenol in soybean and spinach plants. Environ. Res 37: $101-118$.

Cataldo, D.A., R.M. Bean, and RJ. Fellows. 1986. Uptake and fate of phenol, aniline and quinoline in terrestrial plants. In Twenty-Fourth Hanford Life Sciences Symposium on Health and Environmental Research on Complex Organic Mixtures (in press).

Chafe, S.C. and A.B. Wardrop. 1972. Fine structural observations on the epidermis. I. The epidermal cell wall. Planta 107:269-278.

Chamberlain, A.C. 1966. Transport of gases to and from grass and grass-like surfaces. Proc. Royal Soc. Vol. A290. 236-265.

Chamberlain, A.C. 1975. The movement of particles in plant canopies. In Vegetation and the Atmosphere. ed. J.L. Monteith. 155-228. Academic Press, London.

Cionco, R. M. 1985. Modeling Windfields and surface layer wind profiles over complex terrain and within vegetation canopies. In The Forest-Atmosphere Interaction, eds. B. A. Hutchison and B. B. Hicks, D. Reidel Publishing Company, Boston, MA.

Cooke, J. R., and R.H. Rand. 1980. Diffusion resistance models. In Predicting Photosynthesis for Ecosystem Models. Vol. 1, pp. 93-121. (Eds. Hesketh, J. D., and Jones, J. W.). CRC Press. Boca Raton.

Cowan, I. R. 1977. Stomatal behavior and environment. Adv. Bot. Res. 4:117-228.

Crafts, A.S., and H.G. Rieber. 1948. Herbicidal properties of oils. Hilgardia 18: 77-156.

Crafts, A.S., and W.W. Robbins. 1962. Weed Control. McGraw-Hill Book Comp. NY.

Crank J., and G.S. Park. 1968. Methods of measurement. In: Diffusion in Polymers. eds. J Crank and GS Park. Academic press, New York pp 1-39. 
Currier, H.B., and S.A. Peoples. 1954. Phytotoxicity of hydrocarbons. Hilgardia 23: 155-173.

Davis, D.G., J.S. Mulins, G.E. Stolzenberg, and G.D. Booth. 1979. Permeation of organic inolecules of widely differing solubilities and of water through isolated cuticles of orange leaves. Pestic, Sci. 10:19-31.

Deas, A.H.B. and P.J. Holloway. 1977. The intermolecular structure of some plant cutins. In Lipids and Lipid Polymers in Higher Plants. eds. M Tevini and HK Lichtenthaler., Springer-Verlag, Berlin. pp.293-299.

Doran J. C., and T. W. Horst. 1985. An evaluation of gaussian plume-depletion models with duel-tracer field measurements. Atmos, Environ. 19: 939-951.

Droppo, J. G. 1985. Concurrent measurements of ozone dry deposition using eddy correlation and profile flux methods. J of Geophysical Res., 90, No.D1, 2111-2118.

Droppo, J. G., L. W. Vail, and R. M. Ecker. 1986. INSEA Users Manual. Draft Report submitted by Battelle, Pacific Northwest Laboratory to U.S. Enviromental Protection Agency, Washington, D.C. Available from U.S. EPA, Washington, DC.

Easter R.M. and J.M. Hales. 1984. PLUVIUS: A generalized one-dimensional model of reactive pollutant behaviour including dry deposition, precipitation formation, and wet removal. 2nd ed. MAP3S/RAINE Report, PNL-4046, Pacific Northwest Laboratory, Richland, Washington.

Edwards, N.T. 1986. Uptake, translocation and metabolism of anthracene in bushbean. Environ. Tox. Chem. 5: 659-665.

Edwards, N.T., B.M. Ross-Todd, and E.G. Garver. 1982. Uptake and Metabolism of ${ }^{14} \mathrm{C}$ Anthracene by soybean (Glycine max).Enviton. Exptl, Bot. 22: 349-357.

Esau, K. 1965. Plant Anatomy. 2nd Ed. John Wiley and Sons, New York. 767pp.

Farquhar, G. D. 1978. Feedforward responses of stomata to humidity. Austral. J. Plant Physiol, 5:787-800.

Farquhar, G. D., and T.D. Sharkey. 1982. Stomatal conductance and photosythesis. Ann. Rev, of Plant Physiol, 33:317-345.

Fisher, M. S., D.A. Charles-Edwards, and M.M. Ludlow. 1981. An analysis of effects of repeated short-term soil water deficits on stomatal conductance to carbon dioxide and leaf photosynthesis by the legume Macroptilium atropureum c. v. Siratro. Austral. J. Plant Physiol. 8:347-357. 
Friedlander, S.K., J.R. Turner and S.V. Hering. 1986. A new method for estimating dry deposition velocities for atmospheric aerosols. J. Aerosol Science. 17:240-244.

Gaastra, P. 1959. Photosynthesis of crop plants as influenced by light, carbon dioxide, temperature, and stomatal diffusion resistance. Meded. Landbouwhogesch. Wageningen 59:1-68.

Garland, J.A. 1983. Dry deposition of small particles in two grasses in field conditions. In Precipitation Scavenging. Dry Deposition, and Resuspension: Vol.2 Dry deposition and Resuspension, 1310-1360, Elsevier Press.

Hales, J. M., T. W. Horst and M. T. Dana. 1983. MPADD - A Generalized Code for Reactive Scavenging and Deposition Calculations. U.S. Enviromental Protection Agency, Washington, D.C.

Hallum, N.D. 1982. Fine structure of the leaf cuticle and the origin of leaf waxes. In The Plant Cuticle. eds. D.F. Cutler, K.L. Alvin, and C.E. Price., Academic Press, New York. pp.197-214.

Hamilton, R.J., A.W. McCann, P.A. Sewell, and G.T. Merrall. 1982. Foliar uptake of the wild oat herbicide flamprop-methyl by wheat. In: The Plant Cuticle. eds. D.F Cutler, K.L. Alvin, and C.E. Price. Academic Press, New York. pp. 303-313.

Hanna, S. R., G. A. Briggs, and R. P. Hosker, Jr. 1982. Handbook on Atmospheric Diffusion. Technical Information Center, U.S.Department of Energy, DOE/TIC-11223 (DE82002045).

Hartley, D., and H. Kidd. 1983. The Agrochemicals Handbook, The Royal Society of Chemistry. Unwin Brothers Ltd., Old Woking, Surry, England.

Heath, O. V.S., and T.A. Mansfield. 1962. A recording porometer with detachable cups operating on four separate leaves. Proc. Roy. Soc. A156:1-13.

Hicks, B. B., D.D. Baldocchi, R.P. Hosker Jr., B.A. Hutchinson, D.R. Matt, R.T. McMillen,, and L.C. Satterfield. 1985. On the use of monitored air concentrations to infer dry deposition, NOAA Technical Memorandam ERL ARL-141, Air Resources Laboratory, Silver Spring, Maryland.

Hill, A. C. 1971. Vegetation: A sink for atmospheric pollutants. Journal of the Air Pollution Control Association 21:341-356.

Hoch, H.C. 1979. Penetration of chemicals into the Malus leaf cuticle. An ultrastructural analysis. Planta 147:186-195. 
Holloway, P.J. 1982. Structure and histochemistry of plant cuticular membranes: an overview. In: The Plant Cuticle. DF Cutler, KL Alvin, and CE Price, eds., Academic Press, New York. pp.1-32.

Horst, T. W. 1984. The modification of plume models to account for dry deposition. Boundary-Layer Meteor. 30: 413-430.

Hosker, R. P. 1980. Practical Application of Air Pollution Deposition Models -Current Status, Data Requirements, and Research Needs. In Proceedings of the International Conference on Air Pollutants and Their Effects on the Terrestrial Ecosystem, Banff, Alberta, Canada, May 10-17, 1980, eds. S. V. Krupa and A. H. Legge, John Wiley \& Sons, New York.

Hosker, R. P. and S. E. Lindberg. 1982. Review: Atmospheric Deposition and Plant Assimilation of Gases and Particles." Atmos. Environ. 16:889.

Hsiao, T. C. 1975. Variables affecting stomatal opening - Complicating effects. In Measurement of Stomatal Aperature and Diffusive Resistance. ed. E. T. Kanemasu. College of Agricultural Research Center Bull. 809, Washington State University, Pullman, WA.

Isensee, A.R. and G.E. Jones. 1971. Absorption and translocation of root and foliage applied 2,4-dichlorophenol, 2,7-dichlorodibenzo-p-dioxin, and 2,3,7,8-tetrachlorodibenzo-p-dioxin: J. Agr. Food Chem 19:1210-1214.

Jarvis, P. G. 1971. In Plant Photosynthetic Production: Manual of Methods. 566-570. eds. Z. Sestak, J. Catsky, and P.G. Jarvis, Junk, The Hague.

Jarvis, P. G. 1976. The interpretation of the variations in leaf water potential and stomatal conductance found in canopies in the field. Phil. Trans, Royal Soc. B 273: 593-610.

Jarvis, P. G., H. S. Miranada, and R. I. Muetzelfeldt. 1985, Modeling Canopy Exchanges of Water Vapor and Carbon Dioxide in Coniferous Forest Plantations. In: The Forest-Atmosphere Interaction. eds. B. A. Hutchison and B. B. Hicks, D. Reidel Publishing Company, Boston, MA.

Jensen, K. F., and B.R. Roberts. 1986. Changes on yellow poplar stomatal resistance with $\mathrm{SO}_{2}$ and $\mathrm{O}_{3}$ fumigation. Environ. Pollut. (Series A) 41:235-245.

Kercher, J. R. 1977. Grow1: A crop growth nodel for assessing impacts of gaseous pollutants from geothermal technologies. UCRL-52247:1-33, Lawrence Livermore Laboratory, Livermore, CA.

Kerler, F., M. Reiderer, and J. Schönherr. 1984. Non-electrolyte permeability of plant cuticles: A critical evaluation of experimental methods. Physiol. Plant. 62:599-602. 
Kramer, P. J. 1983. Water Relations of Plants. Academic Press. New York-London.

Kuiper, P. J. C. 1961. The effects of environmental factors on the transpiration of leaves, with special reference to stomatal light response. Meded.

Landbouwhogesch. Wageningen 61:1-49

Kuppers, M., and E.D. Schulze. 1985. An empirical model of net photosynthesis and leaf conductance for the simulation of diurnal courses of $\mathrm{CO}_{2}$ and $\mathrm{H}_{2} \mathrm{O}$ exchange. Austral. J. Plant Physiol, 12:513-526.

Lambertz, P. 1954. Unterschungen über das Vorkommen von Plasodesmen in den Epiderisaussenwänden. Planta 44:147-190.

Lane, D. D. and J. J. Stukel. 1978. Aerosol deposition of a flat plate. J. of Aerosol Sci. (9) 191-197.

Lange, O.L., R. Lösch, E.O. Schulze, and L. Kappen. 1971. Responses of Stomata to Changes in Humidity. Planta 100:76-86.

Larcher, W. 1980. Physiological Plant Ecology. Springer-Verlag. Berlin, Heidelberg and New York.

Lemon, E. 1963. Energy and Water Balance of Plant Communities. In Environmental Control of Plant Growth. ed. L. T. Evans. 79-94, Academic Press, New York.

Leuning, R., M.H. Unsworth, H.N. Neumann and K.M. King, K. M. 1979. Ozone fluxes to tobacco and soil under field conditions. Atmos. Environ. 13:1155-1163.

Levine, S.Z., S.E. Pratsinis, and S. K. Friedlander. 1982. In-cloud and below-cloud scavenging of nitric acid vapor. Atmos, Envir., 16: 1725-1734.

Lewellan, W. S. 1985. Modeling Turbulent Exchange in Forest Canopies. In: The Forest-Atmosphere Interaction, eds. B. A. Hutchison and B. B. Hicks, D. Reidel Publishing Company, Boston, MA.

Lewellen, D. D., and Y.P. Sheng 1982. Modeling of dry depostion of $\mathrm{SO}_{2}$ and sulfate aerosols. EPRI Report EA-1452. Electric Power Research Institute, Palo Alto, CA.

Mansfield, T. A., A.R. Wellburn and T.J.S. Moreira, T. J. S. 1978. The role of abscisic acid and farnesol in the alleviation of water stress. Philos. Trans. R. Soc. London. Ser. B 284:471-482.

McFarlane, C. 1986. Personal Communication. Draft of UTAB Model - April 25, 1986. 
Meidner, H., and D.C. Spanner. 1959. The differential transpiration porometer. Journal of Experimental Botany 10:190-205.

Meidner, H., and T.A. Mansfield. 1968. Physiology of Stomata. Macgraw-Hill, England.

Metzler, J. T., and E.J. Pell. 1980. The impact of peroxyacetyl nitrate on conductance and on associated cellular and foliar symptom expression. Phytopathology 70:934-938.

Mirande, M. 1910. Les effets du goudronnage des route sur la vegetation. C.R. Acad. Sci.Paris. 151: 949-952

Mulawa, P. A., S. H. Cadle, F. Lipari, C. C. Ang, and R.T. Vandervennet. 1986. Urban dew: its composition and influence on dry deposition rates, Atmos. Environ. 20 (7): 1389-1396.

Niki, Y, S. Kuwatsuka, and I. Yokomichi. 1976. Absorption, translocation and metabolism of chlomethoxynil (X-52) in plants. Agr. Biol. Chem. 40: 683-690.

Nobel, P.S. 1974. Introduction to Biophysical Plant Physiology. W. H. Freeman, San Francisco. $487 \mathrm{pp}$.

O'Dell, R. A., M. Taheri and R.L. Kabel. 1977. A model for uptake of pollutants by vegetation. Joumal of the Air Pollution Control Association 27:1104-1109.

Okano, K., T. Fukuzawa, T. Tazaki, and T. Totsuka. $1986 .{ }^{15} \mathrm{~N}$ dilution method for estimating the absorption of atmospheric $\mathrm{NO}_{2}$ by plants. New $\underline{\text { Phytologist }}$ 102:73-84.

Olszyk, D. M., and D.T. Tingey. 1985. Interspecific variation in $\mathrm{SO}_{2}$ flux. Plant Physiology 79: 949-956.

Parkhurst, D. F., P.R. Duncan, D.M. Gates, and F. Kreith. 1968. Wind tunnel modeling of convection of heat between air and broad leaves of plants. Agricul. Meteor 5:33-45

Pohlhausen, E. 1921. Der Warmeaustausch zwischen festen Korpern und Flussigkeiten mit kleiner Reibung und kleiner Warmeleitung. Z. Angew. Math. Mech. 1:115-

Price, C.E. 1974. Penetration and movement within plants of pesticides and other solutes: Uptake mechanisms. Reports of Prog. in Appl. Chem. 1:310-326. 
Price, C.E. 1975. Penetration and movement within plants of pesticides and other solutes: uptake mechanisms. Reports on the Progress of Applied Biol. 1:310-326.

Price, C.E. 1976. Penetration and translocation of herbicides and fungicides in plants. In. Herbicides and fungicides - factors affecting their activity. ed. N.R. McFarlane. Chemical Society Special Publication 29. The Chemical Society, London. pp. 42-66.

Price, C.E. 1978. Movement of xenobiotics in plants - perspectives. In Advances in Pesticide Science. ed. H Geisbuhler. Pergamon Pres, Oxford. pp.401-409.

Price, C.E. 1982. A review of the factors influencing the penetration of pesticides through plant leaves. In The Plant Cuticle. eds. D.F. Cutler, K.L. Alvin and C.E. Price. Academic Press, New York. pp.237-252.

Raschke, L. 1975. Stomatal action. Ann. Rev. of Plant Physiol. 26:309-340.

Raschke, L. 1979. Movements of stomata. In Physiology of Movements. eds. W. Haupt and M. E. Feinleib. Encycl. Plant Physiol. New Ser., Vol. 7, pp. 383-441. Springer-Verlag, Berlin.

Reiderer, M, and J. Schönherr. 1984. Accumulation and transport of (2,4-Dichloophenoxy)acetic acid in plant cuticles. I. Sorption in the cuticular membrane and its components. Ecotoxicol, Environ. Safety 8:236-247.

Reiderer, M., and J. Schönherr. 1985. Acumulation and transport of (2,4-Dichlorophenoxy)acetic acid in plant cuticles. II. Permeability of the cuticular membrane. Ecotoxicol, Environ. Safety 9:196-208.

Reiderer, M., and J. Schönherr. 1986. Covalent binding of chlorophenoxyacetic acids to plant cuticles. Ach. Environ. Contam. Toxicol. 15:97-105.

Reynolds, J. F. and B. Acock. 1985. Predicting the response of plants to increasing carbon dioxide: A critique of plant growth models. Ecol, Modelling 29:107-129.

Roessler, P. G., and R.K. Monson. 1985. Midday depression in net photosynthesis and stomatal conductance in Yucca glauca. Oecologia 67:380-387.

Schack, C. J., S. E. Pratsinis, and S.K. Frielander. 1985. A general correlation for deposition of suspended particles from turbulanet gases to completely rough surfaces. Atmos. Envir. 19: 953-960.

Schnepf, C. 1959. Unterschungen über Darstellung und Bau der Ektodesmen und ihre Beeinflussbarkeit durch stoffiche Faktoren. Planta 52:644-708. 
Schönherr,J., and M.J. Bukovac. 1970. Preferential polar pathways in the cuticle and their relationship to ectodesmata. Planta. 92: 189-207.

Schönherr, J. 1976. Water permeability of isolated cuticular membranes: The effect of $\mathrm{pH}$ and cations on diffusion, hydrodynamic permeability and sizer of polar pores in the cutin matrix. Planta 128: 113-126.

Schönherr, J. 1978. Transcuticular movement of xenobiotics. In: Advances in Pesticide Science. ed. H. Geissbuhler. Pergammon, Oxford. pp. 392-400.

Schönherr, J. 1982. Resistance of plant surfaces to water loss: Transport properties of cutin, suberin and associated lipids. In Encyclopedia of Plant Physiology, Eds., A Pirson and MH Zimmerman, New Series Vol. 12B. Springer-Verlag, Berlin/New York. pp. 153-179.

Scott, B. C. 1982. Theoretical estimates of the scavenging coefficient for soluble aerosol particles as a function of precipitation type, rate, an altitude. Atmos. Envir. 16:1753-1762.

Sehmel, G. A., 1973. Particle eddy diffusivities and deposition velocities for isothermal flow and smooth surfaces. Aerosol Sci. 4, 125-138.

Sehmel, G. A. 1980. Particle and gas dry deposition: a review. Atmos, Environ. 14: 983-1011.

Sehmel, G. A. and W. J. Hodgen. 1978. A model for predicting dry deposition of particles and gases to enviromental surfaces. PNL-SA-6721. Pacific Northwest Laboratory, Richland Washington.

Sims, R.C., and M.R. Overcash. 1983. Fate of polynuclear aromatic compounds (PNAs) in soil-plant systems. In Residue Reviews. Residues of Pesticides and Other Contaminants in the Total Enyironment, eds., F.A. Gunther and J.D. Gunther, Springer-Verlag, New York.

Sharkey, T. D., and K. Raschke. 1980. Effects of phaseic acid and dihydrophaseic acid on stomata and the photosynthetic apparatus. Plant Physiol, 65:291-297.

Sheriff, D. W. 1979. Stomatal aperature and the sensing of the environment by guard cells. Plant, Cell, Environ, 2:15-22.

Slinn, W. G. N. 1983. A potpourri of deposition and resuspension questions, In Precipitation Scavenging. Dry Deposition, and Resuspension: Vol.2 Dry Deposition and Resuspension, 1361-1416, Elsevier Press.

Taylor, G. E., D.T. Tingey, and H.C. Ratsch. 1982. Ozone flux in Glycine max (L.) Merr.: Sites of regulation and relationship to leaf injury. Decologia 53:179-186 
Taylor, G. E., and D.T. Tingey. 1983. Sulfur dioxide flux into leaves of Geranium carolinianum L. Plant Physiol. 72:237-244

Tazaki, T., K. Ishihara, and T. Usijima. 1980. Influence of water stress on the photosynthesis and productivity of plants in humid areas. In Adaptation of Plants to Water and High Temperature Stress. eds. N. C. Tumer, and P. J. Kramer. pp. 309-321, Wiley, New York.

Thom, A. S. 1975. Momentum, mass, and heat exchange of plant communities. Yeg. and the Atmos. 2: 57-109.

Thorp, J. M. and B. C. Scott. 1982. Preliminary calculations of average storm duration and seasonal precipitation rates for the northeast secter of the United States. Atmos. Envir. 16:1763-1774.

Tingey, D. T., and G.E. Taylor Jr. 1982. Variation in plant response to ozone: A conceptual model of physiological events. In Effects of Gaseous Air Pollution in Agriculture and Horticulture. Chapter 6. Butterworth Scientific. London.

Turner, N. C., and PJ. Kramer. 1980. Adaptation of Plants to Water and High Temperature Stress. Wiley, New York

Unsworth, M. H. 1981. The exchange of carbon dioxide and air pollutants between vegetation and the atmosphere. In Blants and their Atmospheric Environment, pp. 111-139. eds. J. Grace, E.D. Ford, and P.G. Jarvis. Blackwell. London.

Unsworth, M. H., P.V. Biscoe, and VJ. Black. 1976. Analysis of gas exchange between plants and polluted atmosphere. In Effects of Air Pollutants on Plants, pp. 5-16. ed. T.A. Mansfield. Cambridge Univ. Press, Cambridge.

Van der Hoven, I. 1968. Deposition of Particles and Gases. In Meteorology and Atomic Energy. ed. Slade, D.H. U.S. Atomic Energy Commission. TID-24190. National Technical Information Service. Springfield, Virginia.

Van Voris, P., T.L. Page, W.H. Richard, J.G. Droppo, and B.E. Vaughan. 1985. Environmental Implications of Trace Element Releases from Canadian Coal-Fired Generating Stations. Canadian Electric Association (CEA), Montreal, Quebec. Final Report. 000G194.

Warrit, B., L.L. Landsberg, and M.R. Thorpe. 1980. Responses of apple leaf stomata to environmental factors. Plant Cell, Environ. 3:13-22.

Wattendorff, J. and P.J. Holloway. 1980. Studies on the ultrastructure and histochemistry of plant cuticles: the cuticular membrane of Agave americana L. in situ. Ann. Bot. 46:13-28. 
Whitehouse, P., P.J. Holloway, and J.C. Caseley. 1982. The epicuticular wax of wild oats in relation to foliar entry of the herbicides diclofop-methyl and difenzoquat. In The Plant Cuticle. ed. D.F. Cutler, K.L. Alvin, and C.E. Price. Academic Press, New York. pp.315-330.

Wiman, B. L. B. 1985. A non-stationary model for sulphur aerosol depletion and deposition in a young spruce stand. Tellus 37B, 230-242.

Wiman, B. L. B., and G. I. Agren. 1986. Aerosol depletion and deposition in forests -- a model analysis. Atmos. Environ. 19 (2): 335-347.

Winner, W. E., and H.A. Mooney. 1980. Ecology of $\mathrm{SO}_{2}$ resistance: I. Effects of fumigations on gas exchange of deciduous and evergreen shrubs. Oecologia 44:290-295.

Winner, W. E., and C.J. Atkinson. 1986. Absorption of air pollution by plants and consequences for growth. Trends Ecol, and Evol, 1:15-18

Zachara, J.M., L.J. Felice, R.G. Riley, F.L. Harrison, and B. Mallon. 1984. The selection of organic chemicals for subsurface transport research. DOE/ER-0217. National Technical Information Service (NTIS), Springfield, Virginia. 
.

,

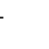


PNL-6173

UC-11

\section{DISTRIBUTION}

No. of

Copies

OFFSITE

40 Dr. Craig McFarlane

U.S. Environmental Protection Agency

Environmental Research Laboratory

Toxics/Pesticide Branch

200 S.W. 35th Street

Corvallis, Oregon 97333

3 DOE Technical Information Center
No. of

Copies

QNSITE

DOE Richland Operations Office

J. J. Sutey

25 Pacific Northwest Laboratory

D. A. Cataldo

D.W. Dragnich

J. G. Droppo

R. J. Fellows

J. M. Hales

P. C. Hays

S. O. Link (5)

R. G. Riley

J. A. Stottlemyre

P. Van Voris (3)

S. G. Weiss

R. E. Wildung

Publishing Coordination (2)

Technical Report Files (5) 




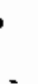





. 